Supporting Information for:

\title{
Asymmetric Synthesis of a Bacteriochlorophyll Model Compound Containing trans-Dialkyl Substituents in Ring D
}

\author{
Khiem Chau Nguyen, ${ }^{\mathrm{a}}$ Pengzhi Wang, ${ }^{\mathrm{a}}$ Roger D. Sommer, ${ }^{\mathrm{b}}$ and Jonathan S. Lindsey ${ }^{\mathrm{a}, *}$ \\ aDepartment of Chemistry \\ North Carolina State University \\ Raleigh, NC 27695-8204 \\ e-mail: jlindsey@ncsu.edu \\ ${ }^{\mathrm{b}}$ Molecular Education, Technology, and Research Innovation Center \\ North Carolina State University \\ Raleigh, NC 27695-8204
}

\section{Table of Contents}

\section{Topic}

1. COSY spectrum of compound $\mathbf{1 2}$

Page

2. NOESY spectra of compounds $14-E$ and $14-Z$

3. Single-crystal X-ray crystallographic data

4. Determination of the molar absorption coefficient of BC-1

5. Assay for chlorin in the bacteriochlorin-forming reaction mixture

6. $\quad{ }^{1} \mathrm{H}$ and ${ }^{13} \mathrm{C}\left\{{ }^{1} \mathrm{H}\right\}$ NMR spectra

S14

S16 


\section{COSY spectrum of compound 12}

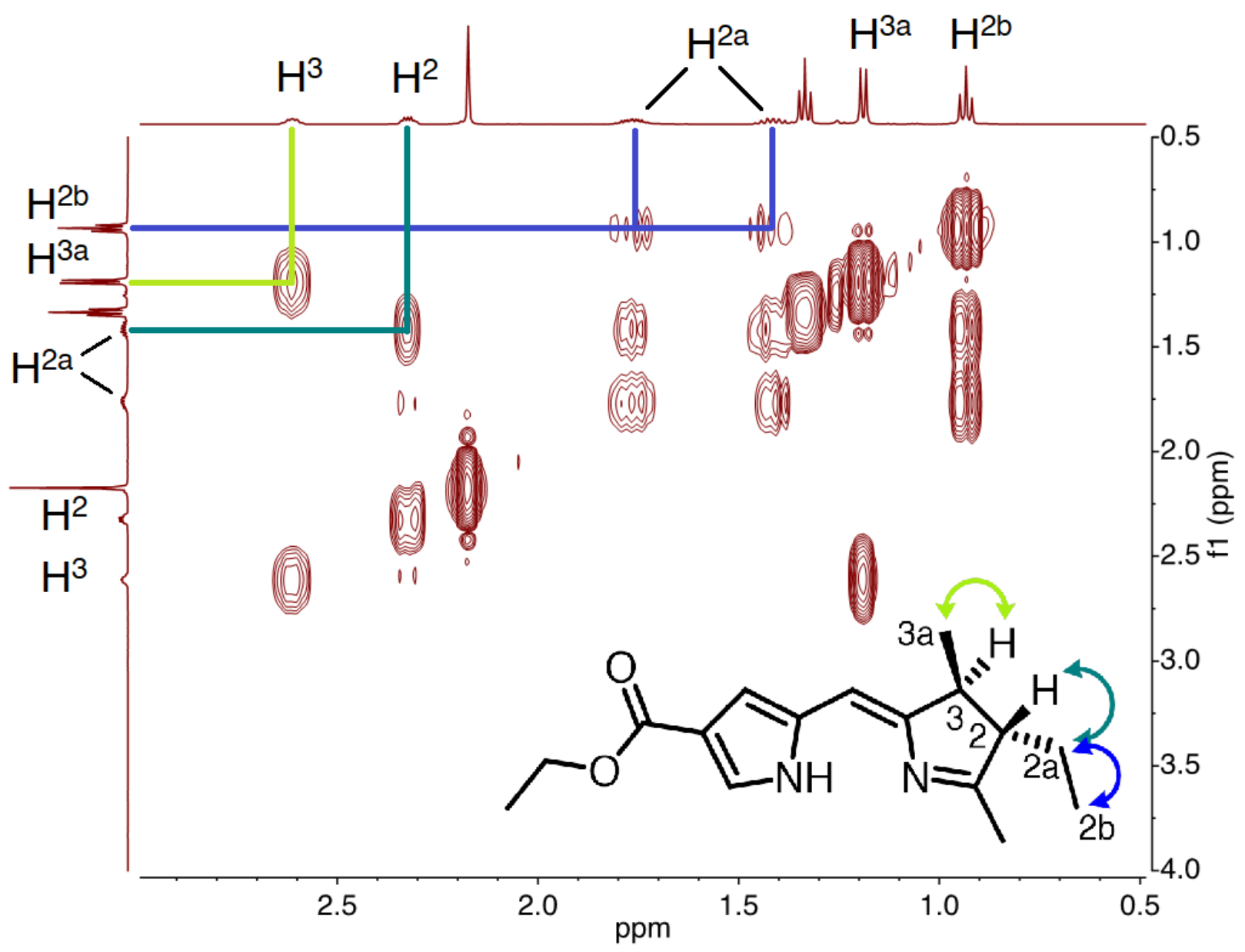

Figure S1. COSY correlations of selected protons at stereocenters of 12. As indicated, the more deshielded multiplets at 2.62 and $2.33 \mathrm{ppm}$ derive from $\mathrm{H}^{3}$ and $\mathrm{H}^{2}$, respectively, while the multiplets located in the range below 2 ppm stem from two $\mathrm{H}^{2 \mathrm{a}}$ atoms. 


\section{NOESY spectra of compounds $14-E$ and $14-Z$}

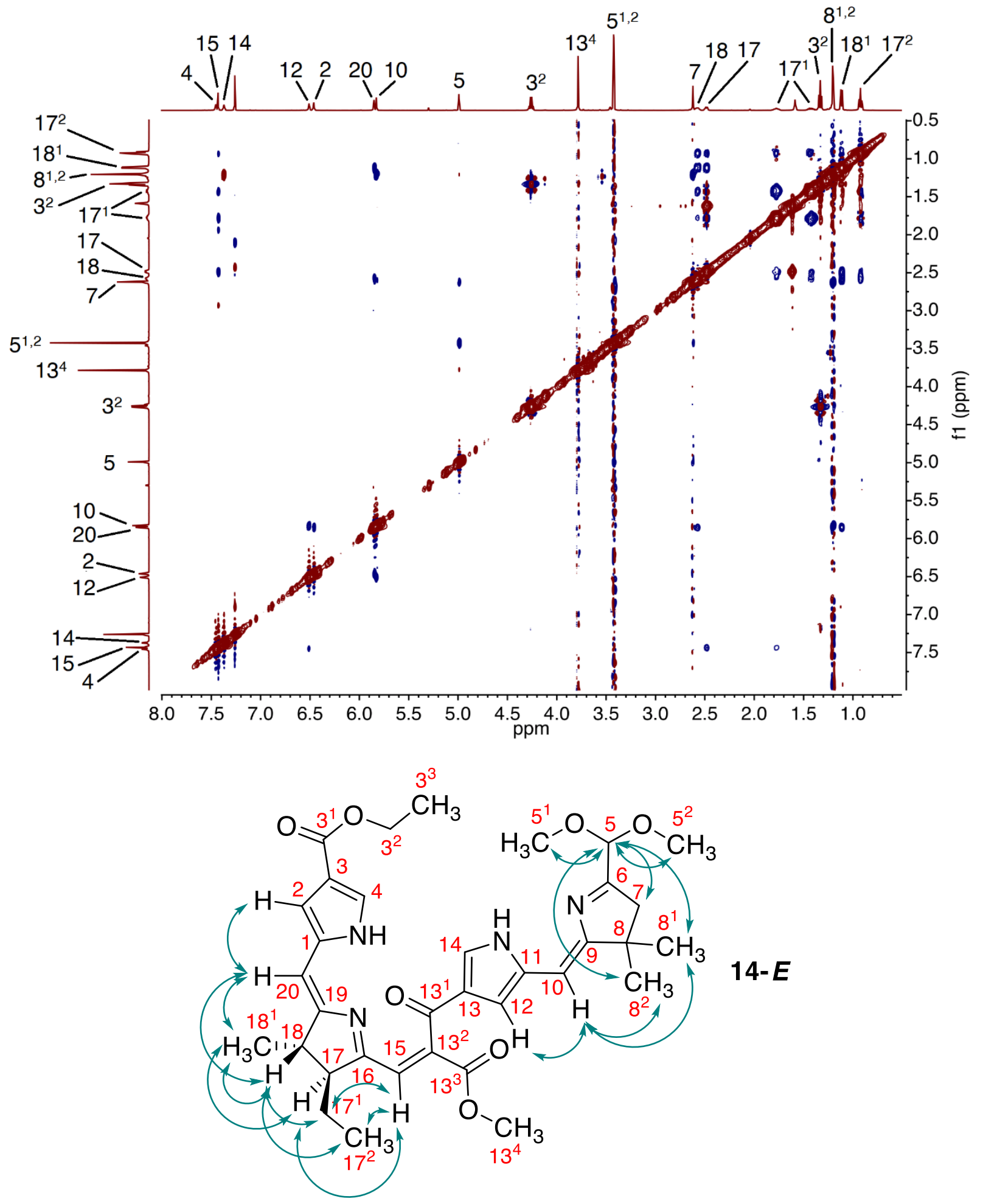

Figure S2. NOESY spectrum and observed correlations in compound 14-E 

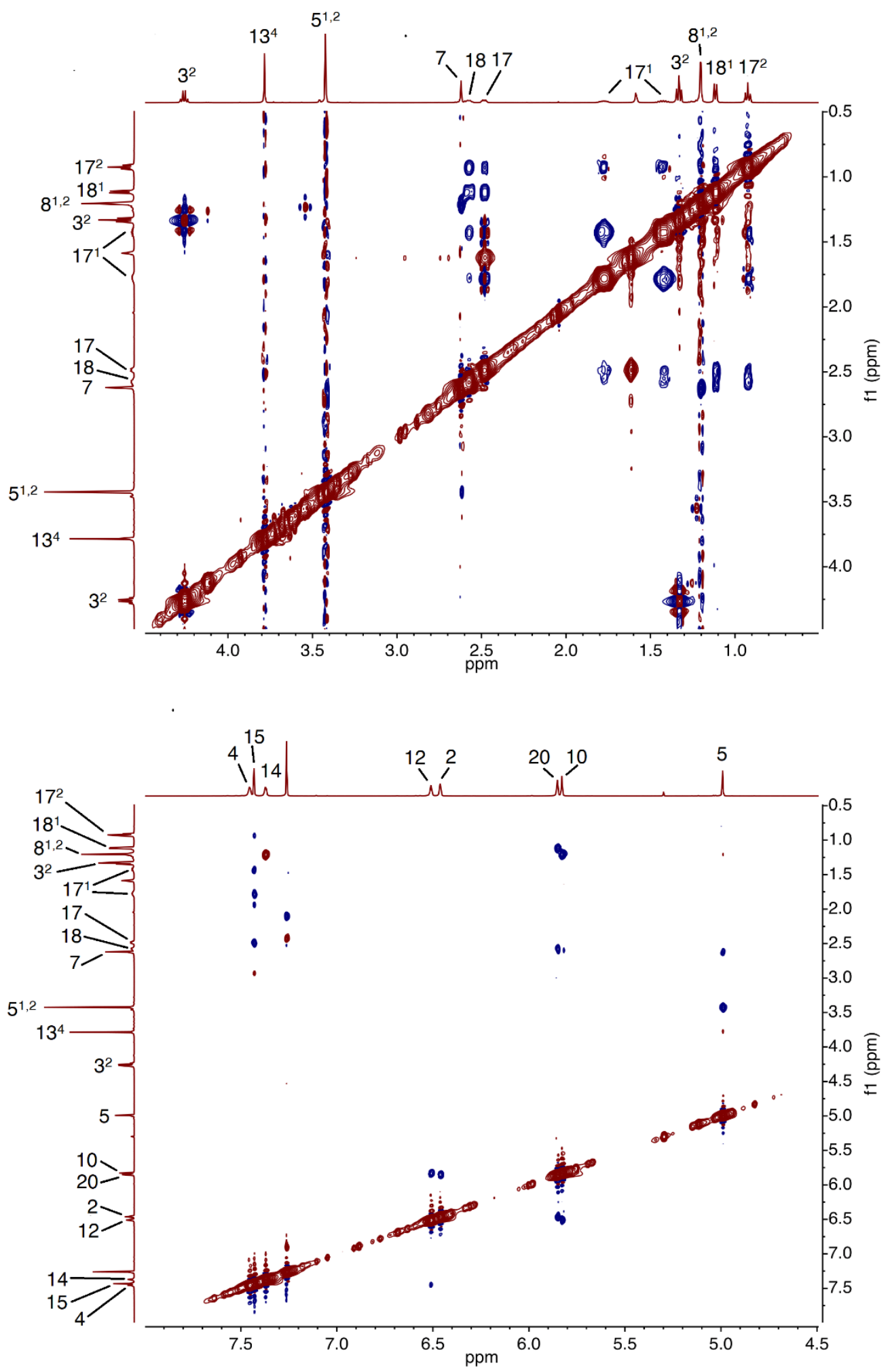

Figure S3. NOESY spectrum and observed correlations in compound 14-E 

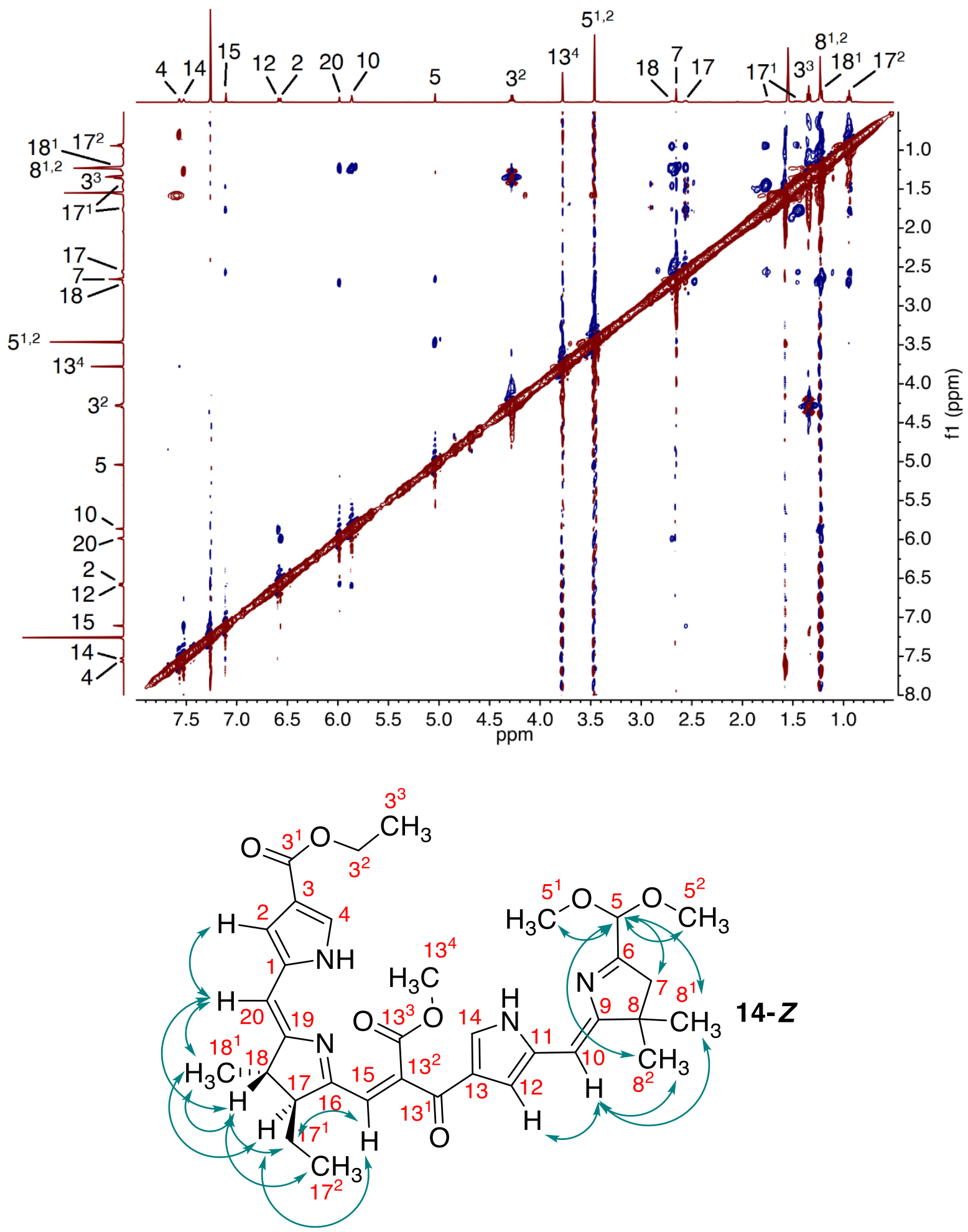

Figure S4. NOESY spectrum and observed correlations in compound 14- $Z$ 

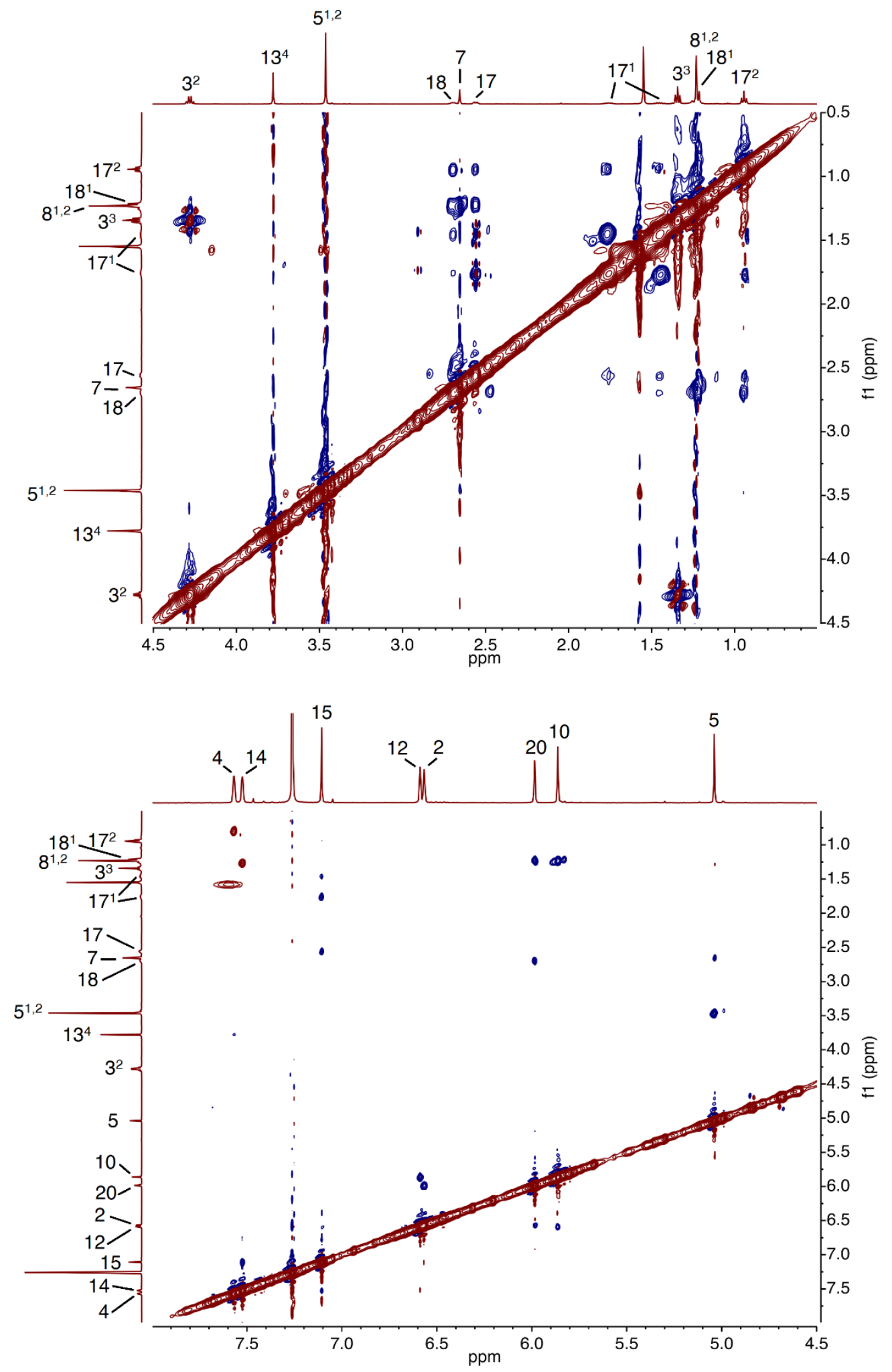

Figure S5. NOESY spectrum and observed correlations in compound $\mathbf{1 4 - Z}$ 


\section{Single-crystal X-ray crystallographic data}

X-Ray Structure Determination: A sample of $\mathbf{1 4 - E}$ was subjected to crystallization following the protocol described in the text. Six crystallization vials were prepared (Figure S6).

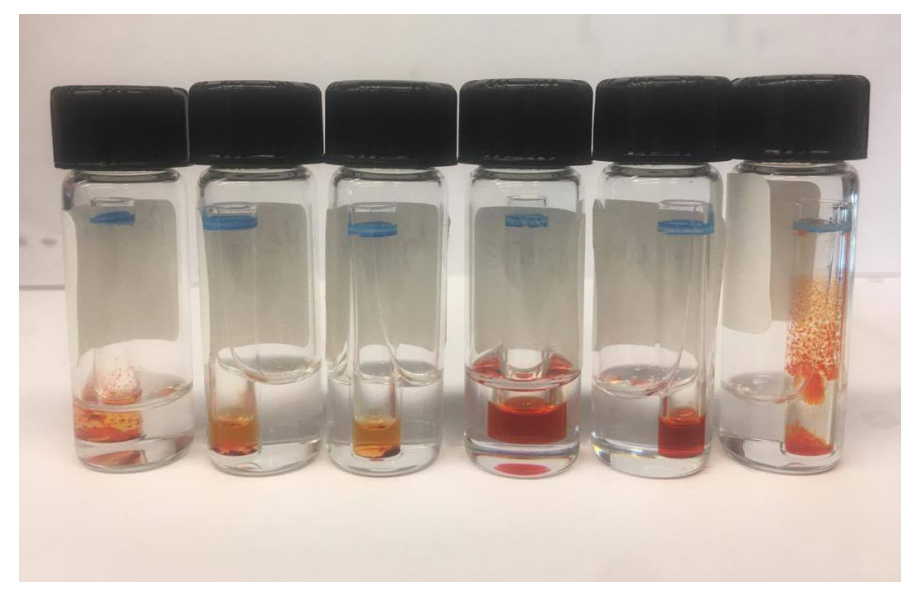

Figure S6. Crystallization vials for vapor-diffusion into the insert vials containing 14- $\boldsymbol{E}$ in acetonitrile. The bulk solvent is as follows (from left to right): pentane, hexane, heptane, benzene, toluene, and diethyl ether.

A representative (orange, rod-like) single crystal of $\mathbf{1 4}-\boldsymbol{E}$, measuring $0.033 \times 0.078 \times 0.128$ $\mathrm{mm}$ was harvested from the mother liquor of the vial containing acetonitrile/diethyl ether and mounted on a $35 \mu \mathrm{m}$ MiTeGen mount. Data were collected on a Bruker D8 Venture diffractometer equipped with a Photon III detector by $\omega$ and $\phi$ scans using $\mathrm{CuK} \alpha$ radiation $(\lambda=1.54178 \AA$ ). Corrections for Lorentz, polarization effects, and absorption were made using SADABS. ${ }^{\mathrm{S} 1}$ The structure was solved using XT, and refined using full-matrix least squares (on $F^{2}$ ) using the SHELX ${ }^{\mathrm{S} 2}$ software package. Absolute stereochemistry was confirmed by Flack and Parson's quotient. ${ }^{\mathrm{S} 3}$ All non-hydrogen atoms were refined anisotropically. Alkyl and aryl $\mathrm{H}$ atoms were added at calculated positions, with coordinates and $\mathrm{U}_{\text {iso }}$ values allowed to ride on the parent atom. $\mathrm{H}$ atoms that participate in hydrogen bonding were not allowed to refine due to already low dataparameter ratio of the structure.

14- $\boldsymbol{E}$ : Compound 14- $\boldsymbol{E}$ crystallized in the space group $P 2_{1}$, with two molecules in the asymmetric unit. The atom numbering system is shown in Figure S7. A representative thermal ellipsoid plot $^{\mathrm{S} 4}$ is shown in Figure S8. The two molecules in the asymmetric unit are shown in Figures S9-S11. Both residues in the asymmetric unit adopt the $E$ geometry at the C11-C12 double bond. Intramolecular hydrogen bonding between N1-N4, and N4-O3 pairs in both residues is noted, potentially stabilizing the enone geometry. Both residues in the asymmetric unit have regions of disorder. The A ring of residue 1 is positionally disordered by rotation around the $\mathrm{C} 20-\mathrm{C} 22$ bond (ester group) and a shift in the A ring. The methoxy $\mathrm{C} 25$ is also disordered on residue 1 . The $\mathrm{B}$ ring of residue 2 is disordered via a twist in the gem-dimethyl group. The $\mathrm{D}$ ring of residue 2 is also disordered over two positions. Refinement of the disordered groups in the structure is stabilized by numerous restraints and constraints, including SAME/SADI/SIMU instructions. C16a requires EADP constraints for stable refinement. A global rigid bond restraint (RIGU) instruction is included in the refinement. Selected crystallographic data are provided in Table S1. 
Table S1. Single-crystal X-ray crystallographic data for compound 14-E.

\begin{tabular}{|l|l|}
\hline CCDC deposition number & 1988555 \\
\hline Chemical formula & $\mathrm{C}_{34} \mathrm{H}_{42} \mathrm{~N}_{4} \mathrm{O}_{7}$ \\
\hline Formula weight $(\mathrm{g} / \mathrm{mol})$ & 618.71 \\
\hline Temperature $(\mathrm{K})$ & 100 \\
\hline Wavelength $(\AA)$ & 1.54178 \\
\hline Crystal size $(\mathrm{mm})$ & $0.13 \times 0.08 \times 0.03$ \\
\hline Crystal habit & Orange rod \\
\hline Crystal system & Monoclinic \\
\hline Space group & $P 2_{1}$ \\
\hline Unit cell dimensions, $a(\AA)$ & $14.5879(4)$ \\
\hline Unit cell dimensions, $b(\AA)$ & $10.2102(3)$ \\
\hline Unit cell dimensions, $c(\AA)$ & $23.8219(7)$ \\
\hline$\alpha$, deg & 90 \\
\hline$\beta$, deg & $106.882(2)$ \\
\hline$\gamma$, deg & 90 \\
\hline Volume $\left(\AA^{3}\right)$ & $3395.25(17)$ \\
\hline$Z$ & 4 \\
\hline Density $($ calculated $)\left(\mathrm{g} / \mathrm{cm}^{3}\right)$ & 1.210 \\
\hline Absorption coefficient $\left(\mathrm{mm}^{-1}\right)$ & 0.696 \\
\hline $\mathrm{F}(000)$ & 1320 \\
\hline Theta range for data collection, deg & 1.94 to 70.19 \\
\hline Index ranges & $-17 \leq \mathrm{h} \leq 17,-12 \leq \mathrm{k} \leq 12,-29 \leq 1 \leq 27$ \\
\hline Reflection collected & 73367 \\
\hline Independent reflections & $12867[\mathrm{R}(\mathrm{int})=0.075]$ \\
\hline $\mathrm{R}_{1}$ & 0.0482 \\
\hline wR & 0.1220 \\
\hline $\mathrm{R}_{1}($ all data) & 0.0630 \\
\hline wR 2 (all data) & 0.1322 \\
\hline Largest diff. peak and hole $\left(\mathrm{e} \AA^{-3}\right)$ & 0.623 and -0.238 \\
\hline R.M.S. deviation from $\mathrm{mean}^{-3}\left(\mathrm{e} \AA^{-3}\right)$ & 0.045 \\
\hline Absolute structure parameter & \\
\hline & $0.03(8)$ \\
\hline & \\
\hline
\end{tabular}

\section{$\mathrm{X}$-ray References}

(S1) Bruker-AXS Inc. (2019), Madison Wisconsin, USA.

(S2) Sheldrick, G. M. SHELXT - Integrated Space-Group and Crystal-Structure Determination. Acta Cryst. 2015, A71, 3-8.

(S3) Parsons, S.; Flack, H. D.; Wagner, T. Use of Intensity Quotients and Differences in Absolute Structure Refinement. Acta Cryst. 2013, B69, 249-259.

(S4) Dolomanov, O. V.; Bourhis, L. J.; Gildea, R. J.; Howard, J. A. K.; Puschmann, H. OLEX2: A Complete Structure Solution, Refinement and Analysis Program. J. Appl. Cryst. 2009, $42,339-341$. 


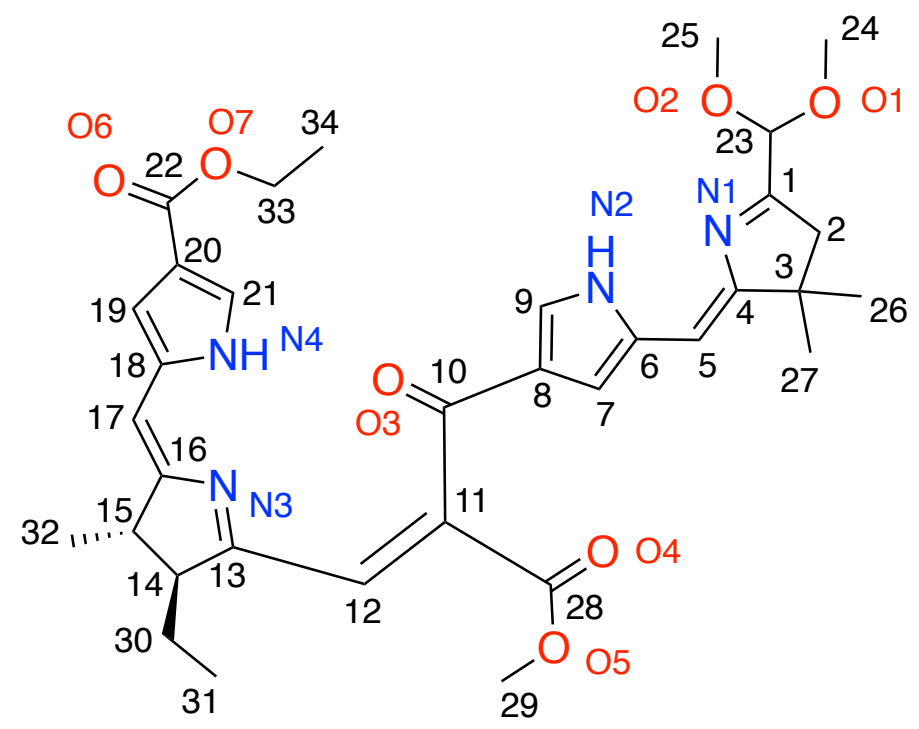

Figure S7. Atom numbering system for $14-E$ in the X-ray discussion herein. The "C" prefix for the carbon numbers is omitted in this diagram for clarity.

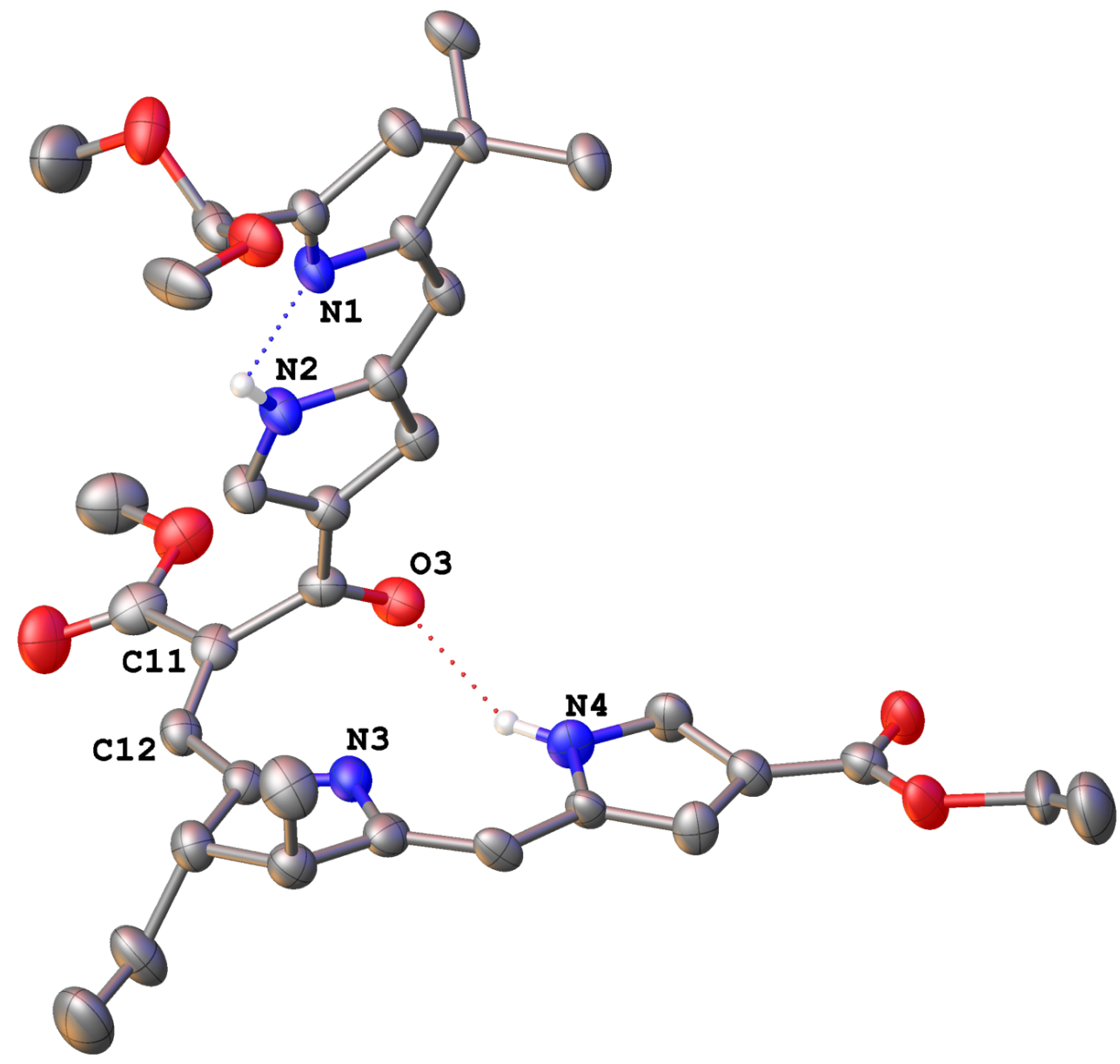

Figure S8. A representative thermal ellipsoid $\mathrm{plot}^{\mathrm{S} 4}$ (50\%) for $\mathbf{1 4 - E}$. Only selected atoms are labeled. Most $\mathrm{H}$ atoms, and disordered groups, are hidden for clarity. 


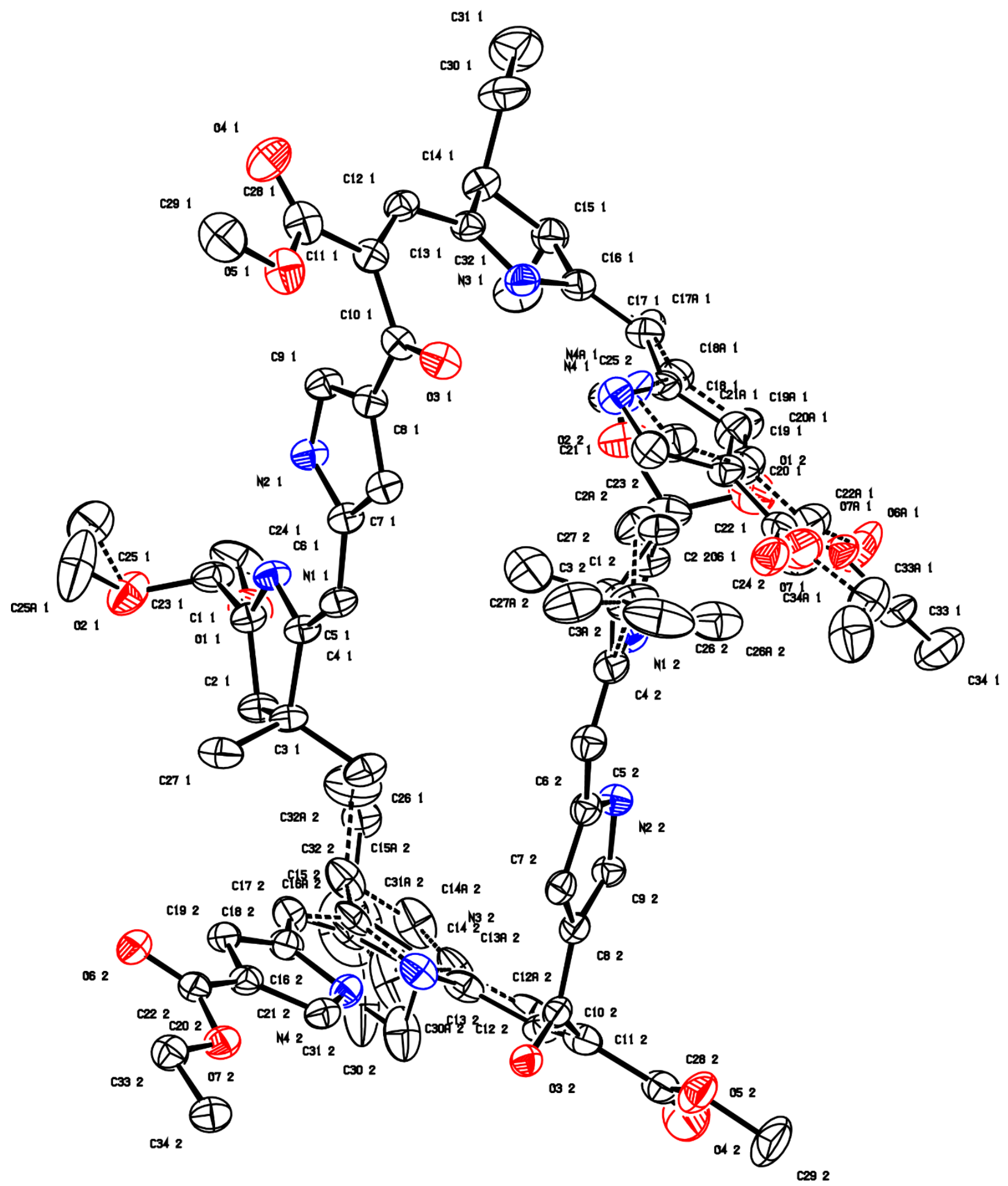

Figure S9. ORTEP diagram showing two molecules (marked with the extension number 1 and 2) of compound 14- $\boldsymbol{E}$ with thermal ellipsoids drawn at the $50 \%$ probability level. Hydrogen atoms were omitted for clarity. 


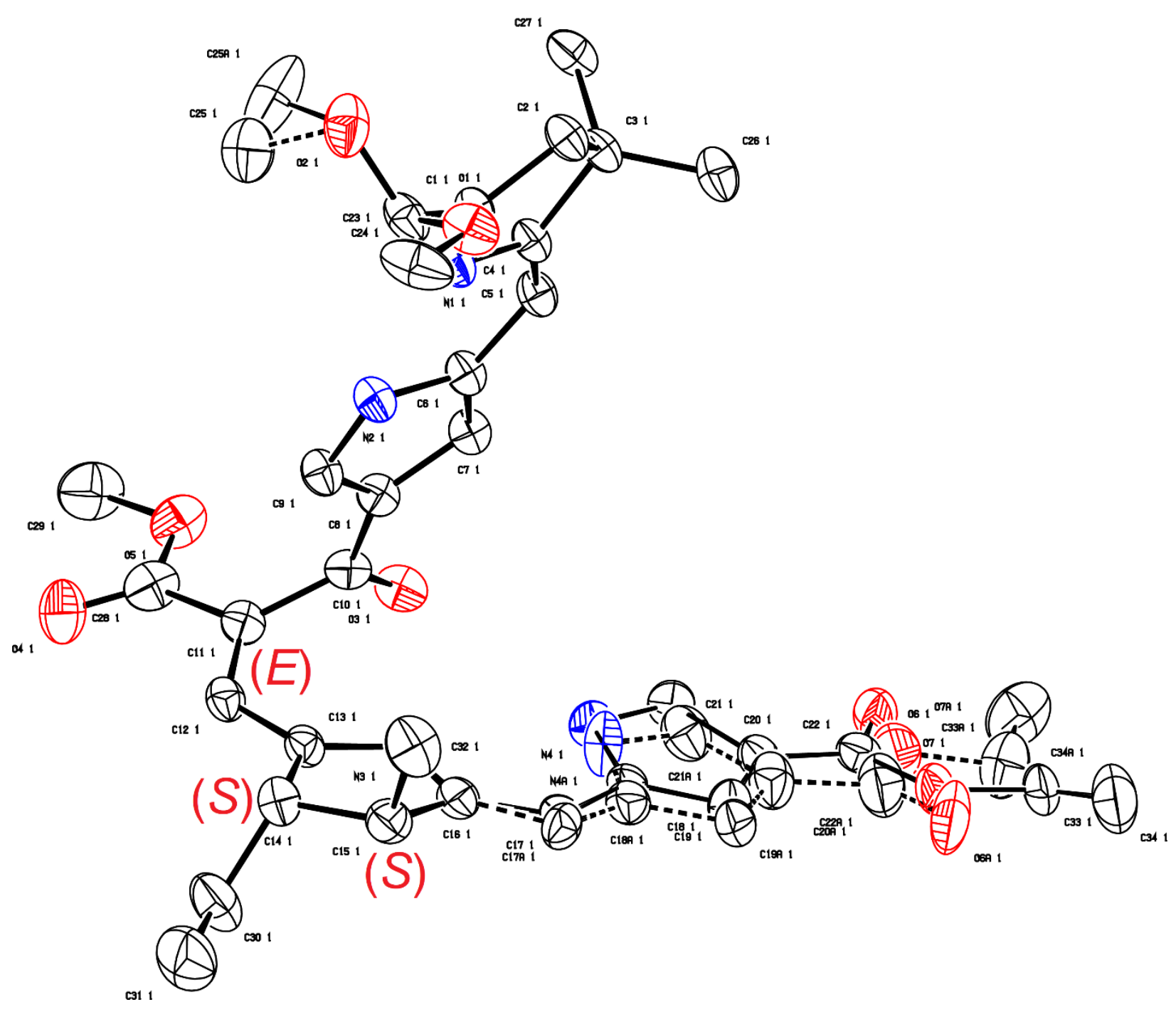

Figure S10. Best view displaying the $E$ configuration of the enone double bond and the $(S, S)$ stereochemistry of the trans-dialkyl substituents in molecule 1 of compound 14-E. 


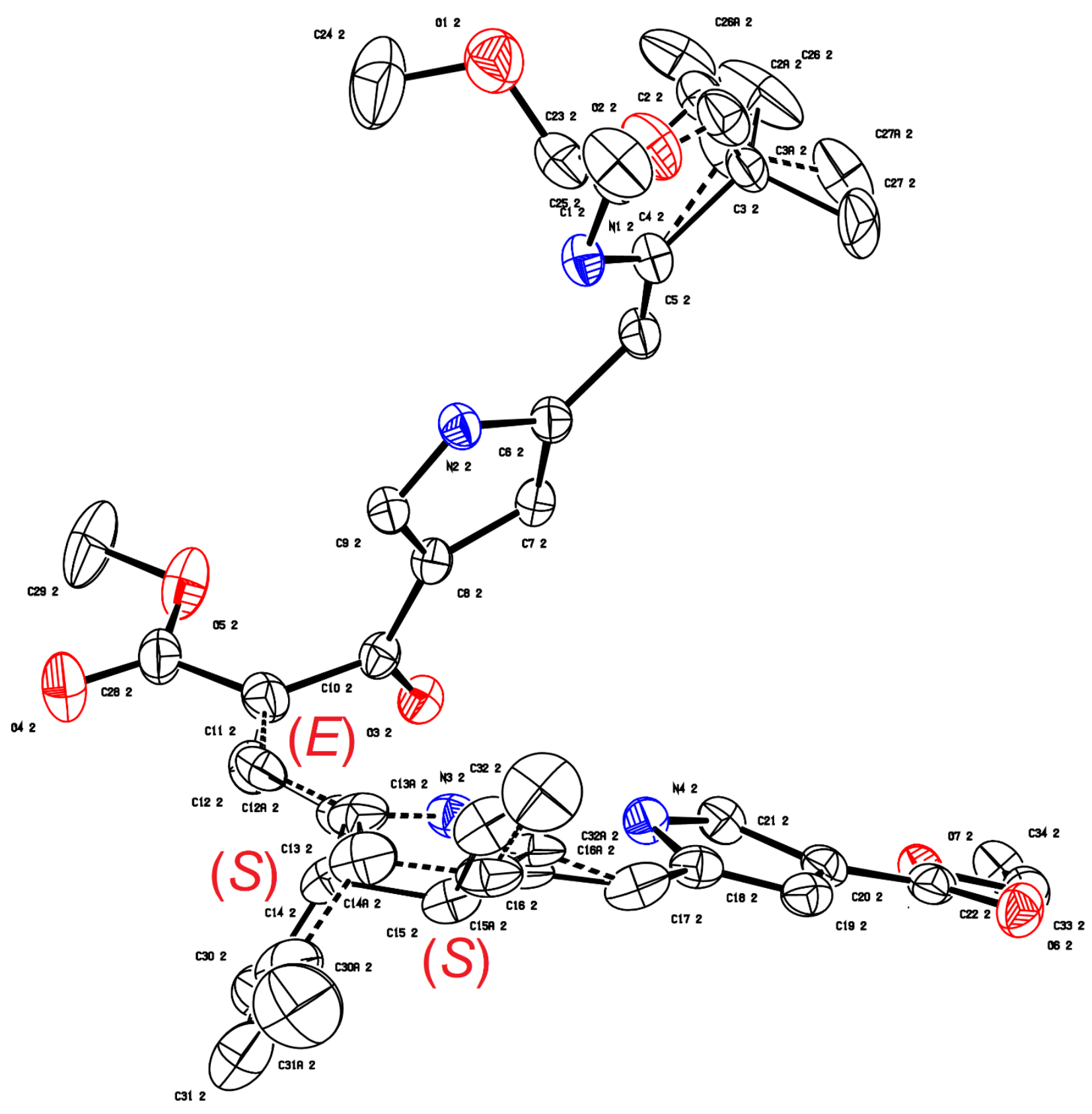

Figure S11. Best view displaying the $E$ configuration of the enone double bond and the $(S, S)$ stereochemistry of trans-dialkyl substituents in molecule 2 of compound 14-E. 


\section{Determination of the molar absorption coefficient of BC-1}
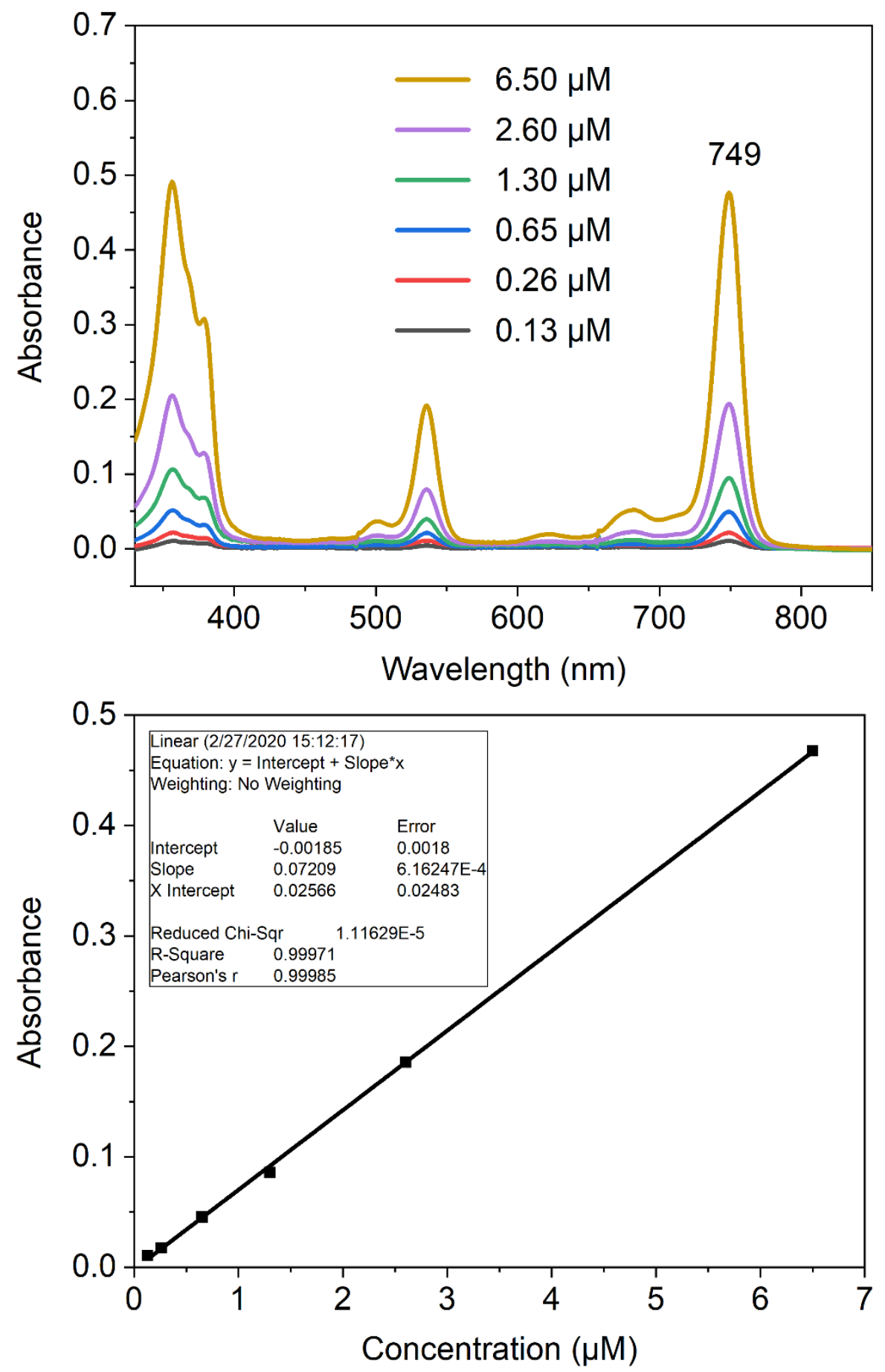

Figure S12. Absorption spectra of BC-1 at concentrations from $0.13 \mu \mathrm{M}$ to $6.50 \mu \mathrm{M}$ in toluene (top), and concentration dependence of the absorbance of BC-1 $(\lambda=749 \mathrm{~nm})$. 


\section{Assay for chlorin in the bacteriochlorin-forming reaction mixture}
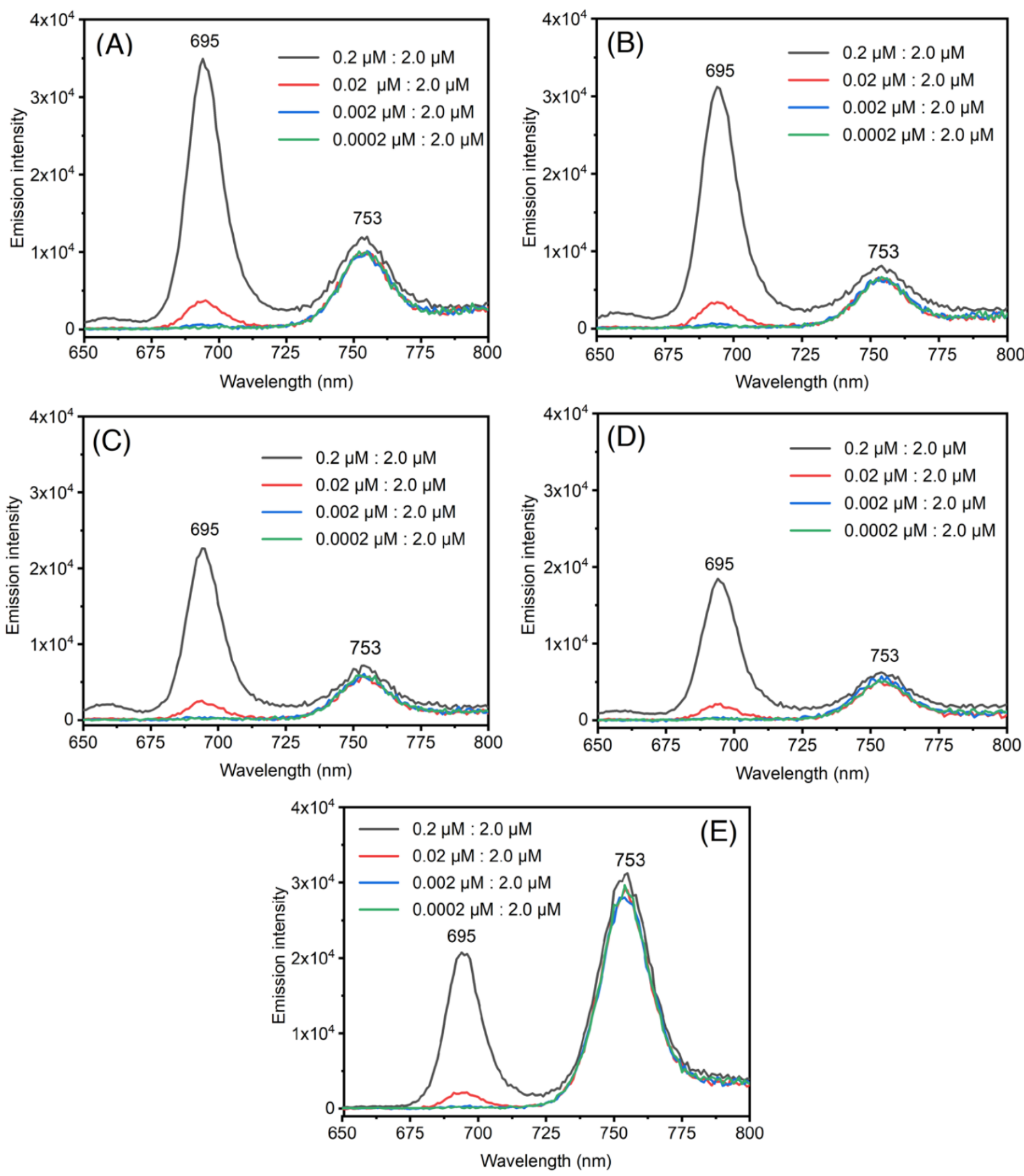

Figure S13. Excitation wavelength survey with excitation at $406 \mathrm{~nm}$ (A), $420 \mathrm{~nm}(\mathrm{~B}), 430 \mathrm{~nm}$ (C), $440 \mathrm{~nm}$ (D), and $553 \mathrm{~nm}$ (E) for mock samples containing C-1 at various concentrations along with bacteriochlorin BC-1. In each sample, the concentration of BC-1 was fixed at $2.0 \mu \mathrm{M}$ while the concentration of $\mathbf{C}-1$ was varied from $0.2 \mu \mathrm{M}-0.0002 \mu \mathrm{M}$. The concentrations are listed in each graph in the format $[\mathbf{C}-1]:[\mathbf{B C}-\mathbf{1}]$. 


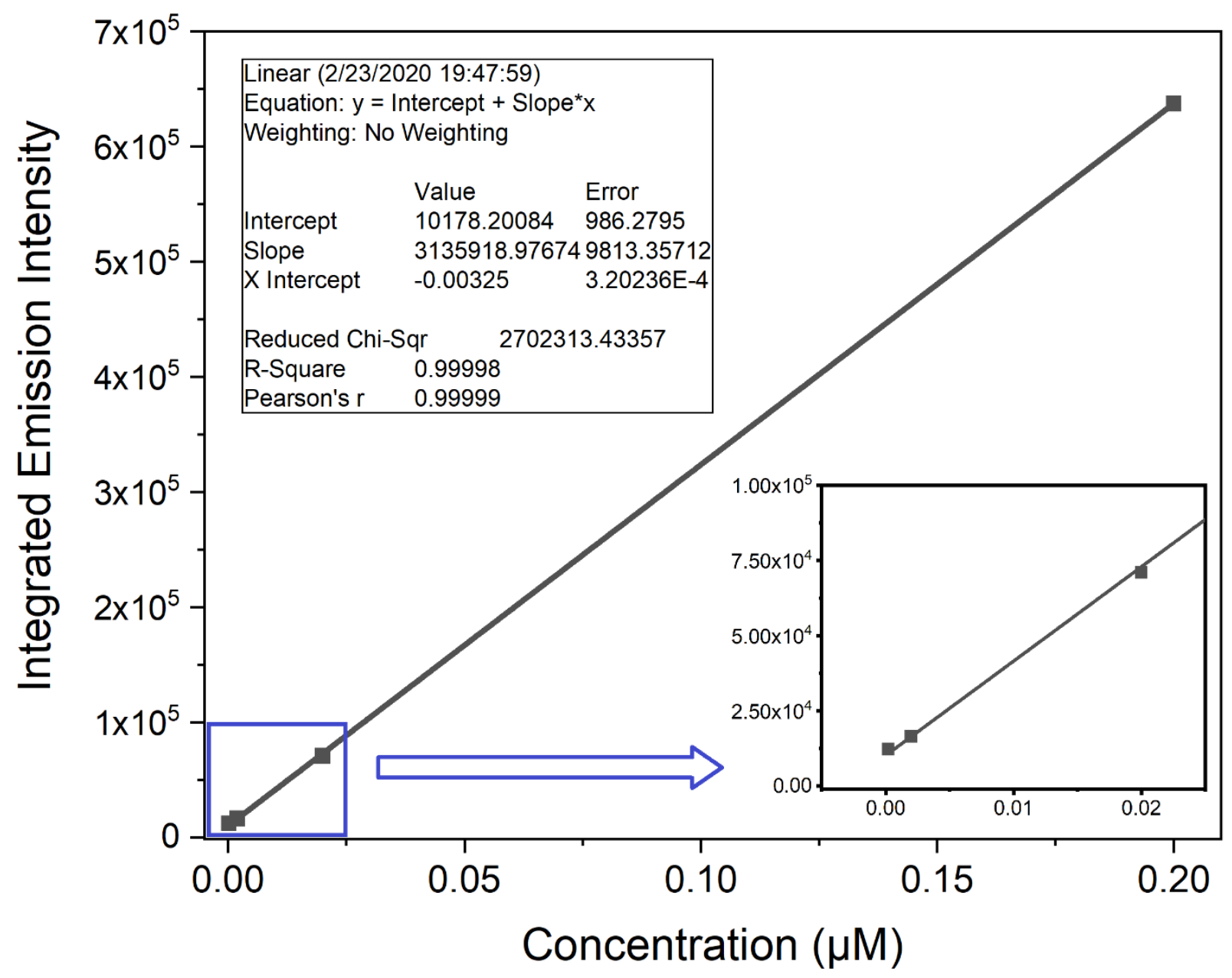

Figure S14. A linear dependence of integrated emission intensity of C-1 on concentration in mock solutions. 
6. ${ }^{1} \mathrm{H}$ and ${ }^{13} \mathrm{C}\left\{{ }^{1} \mathrm{H}\right\}$ NMR spectra

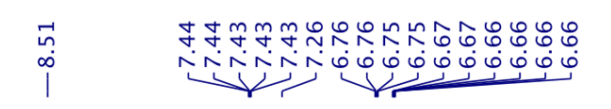

${ }^{1} \mathrm{H} \mathrm{NMR}\left(\mathrm{CDCl}_{3}, 500 \mathrm{MHz}\right)$
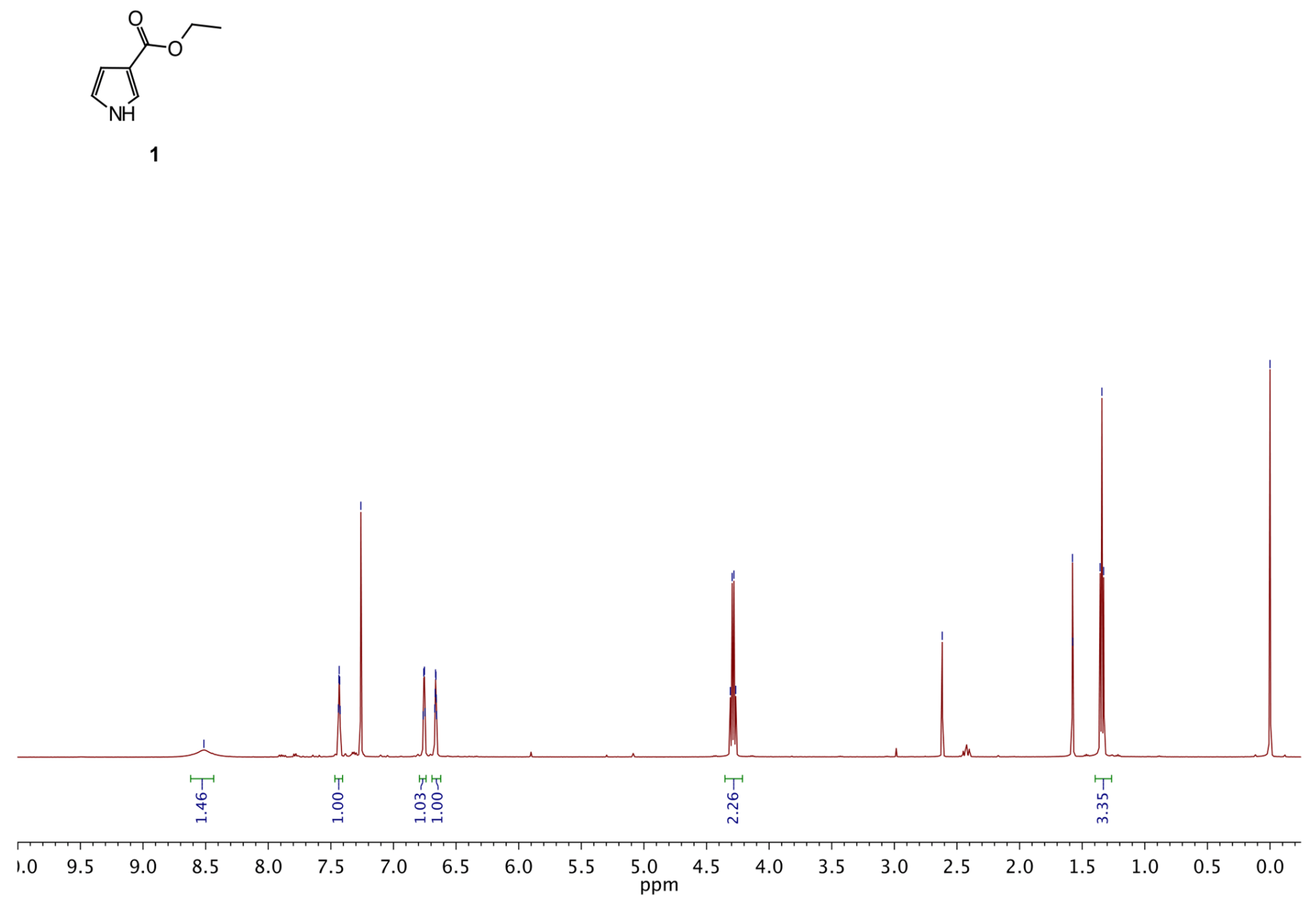


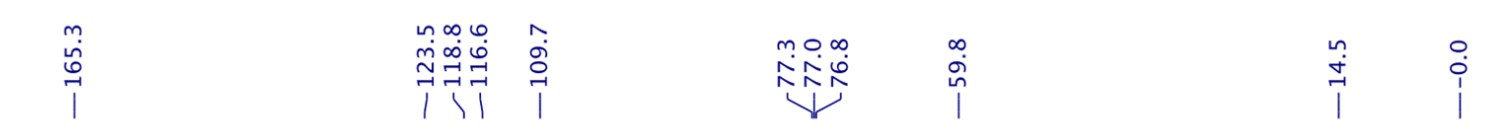

${ }^{13} \mathrm{C}\left\{{ }^{1} \mathrm{H}\right\} \mathrm{NMR}\left(\mathrm{CDCl}_{3}, 125 \mathrm{MHz}\right)$
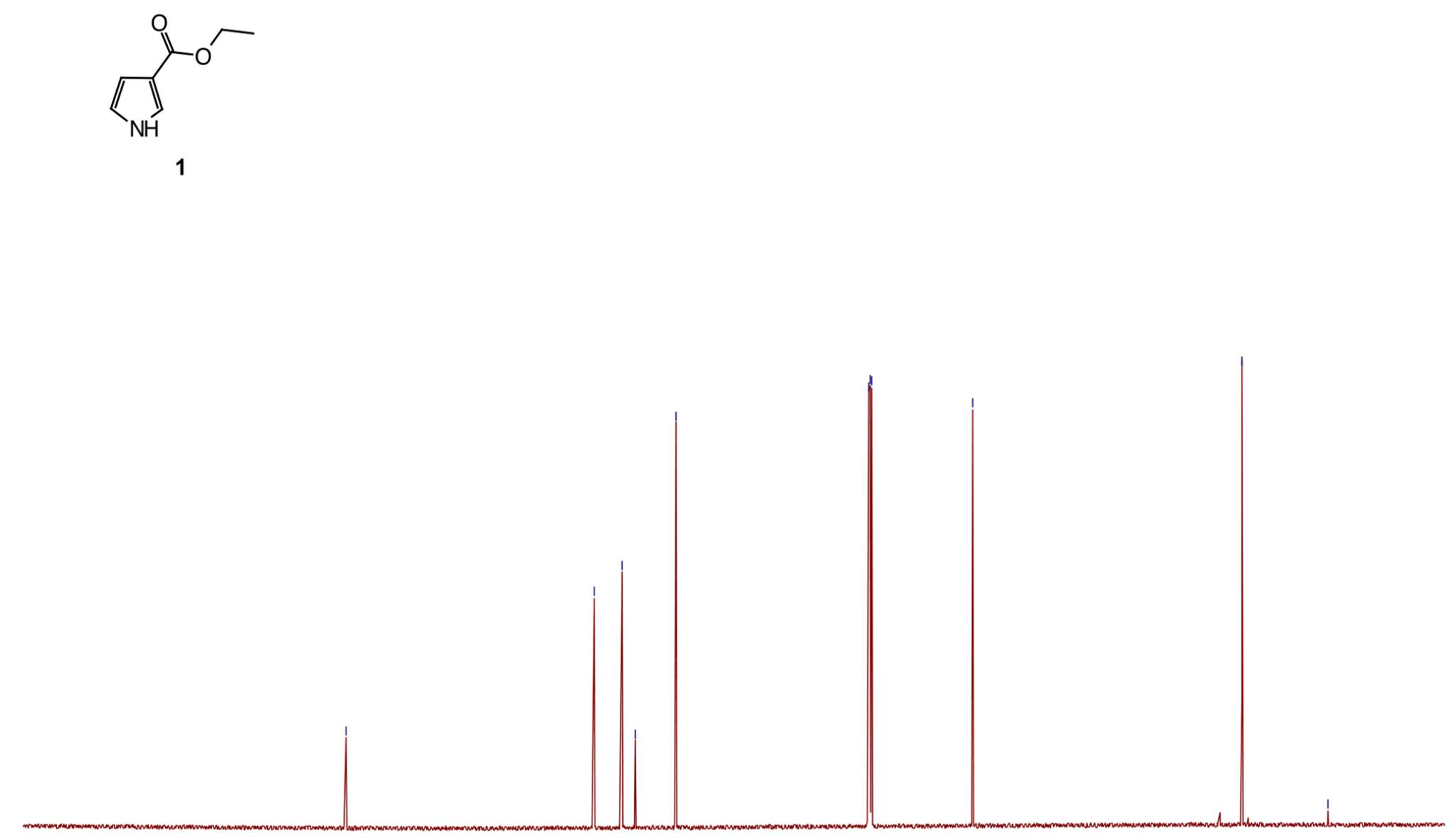

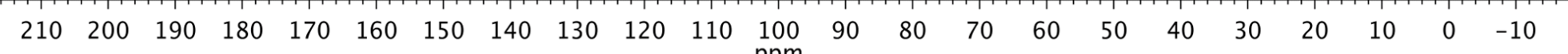




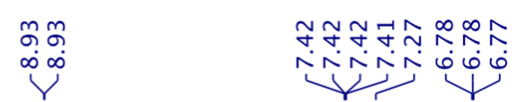

${ }^{1} \mathrm{H} \mathrm{NMR}\left(\mathrm{CDCl}_{3}, 500 \mathrm{MHz}\right)$
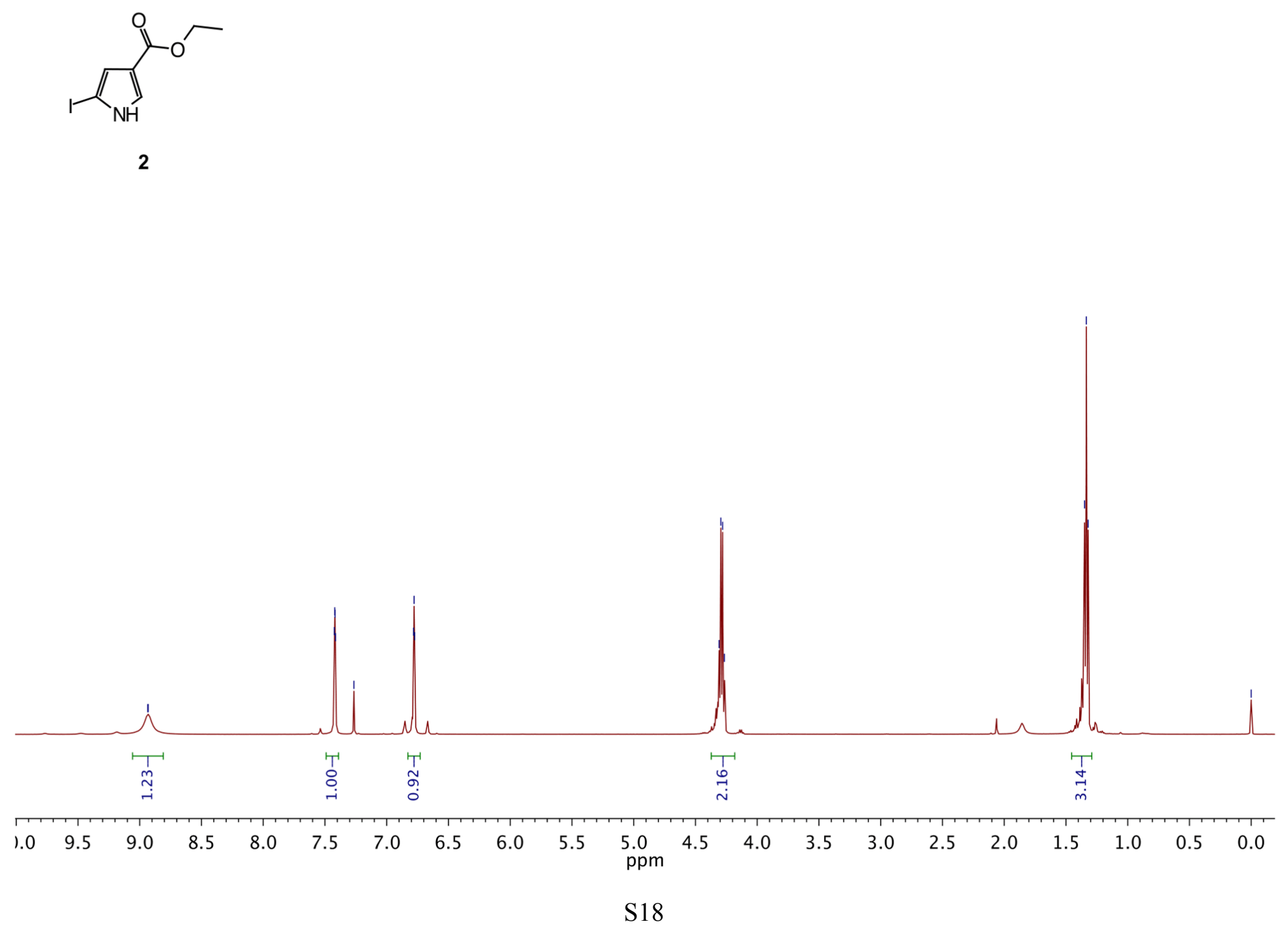


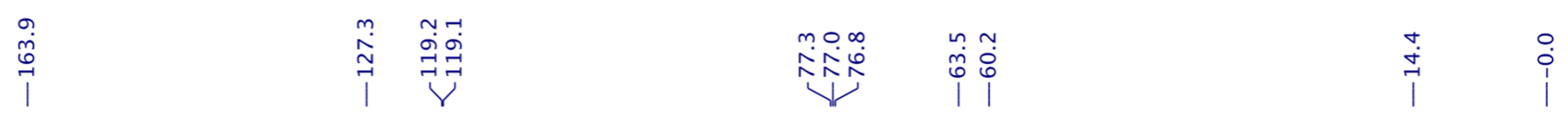

${ }^{13} \mathrm{C}\left\{{ }^{1} \mathrm{H}\right\} \mathrm{NMR}\left(\mathrm{CDCl}_{3}, 125 \mathrm{MHz}\right)$

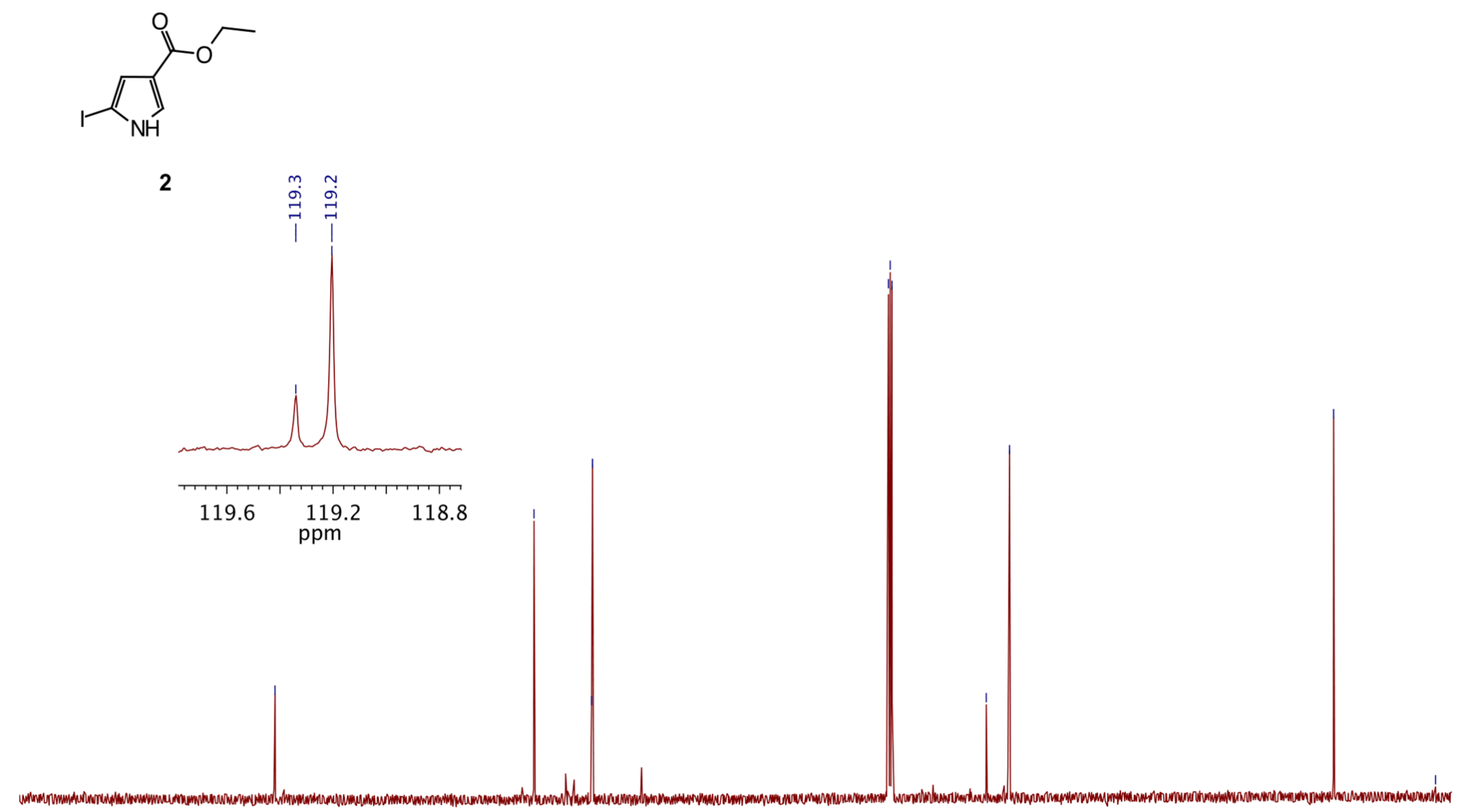

$\begin{array}{lllllllllllllllllllll}30 & 190 & 180 & 170 & 160 & 150 & 140 & 130 & 120 & 110 & \begin{array}{c}100 \\ \mathrm{ppm}\end{array} & 90 & 80 & 70 & 60 & 50 & 40 & 30 & 20 & 10 & 0\end{array}$ 
${ }^{1} \mathrm{H} \mathrm{NMR}\left(\mathrm{CDCl}_{3}, 500 \mathrm{MHz}\right)$
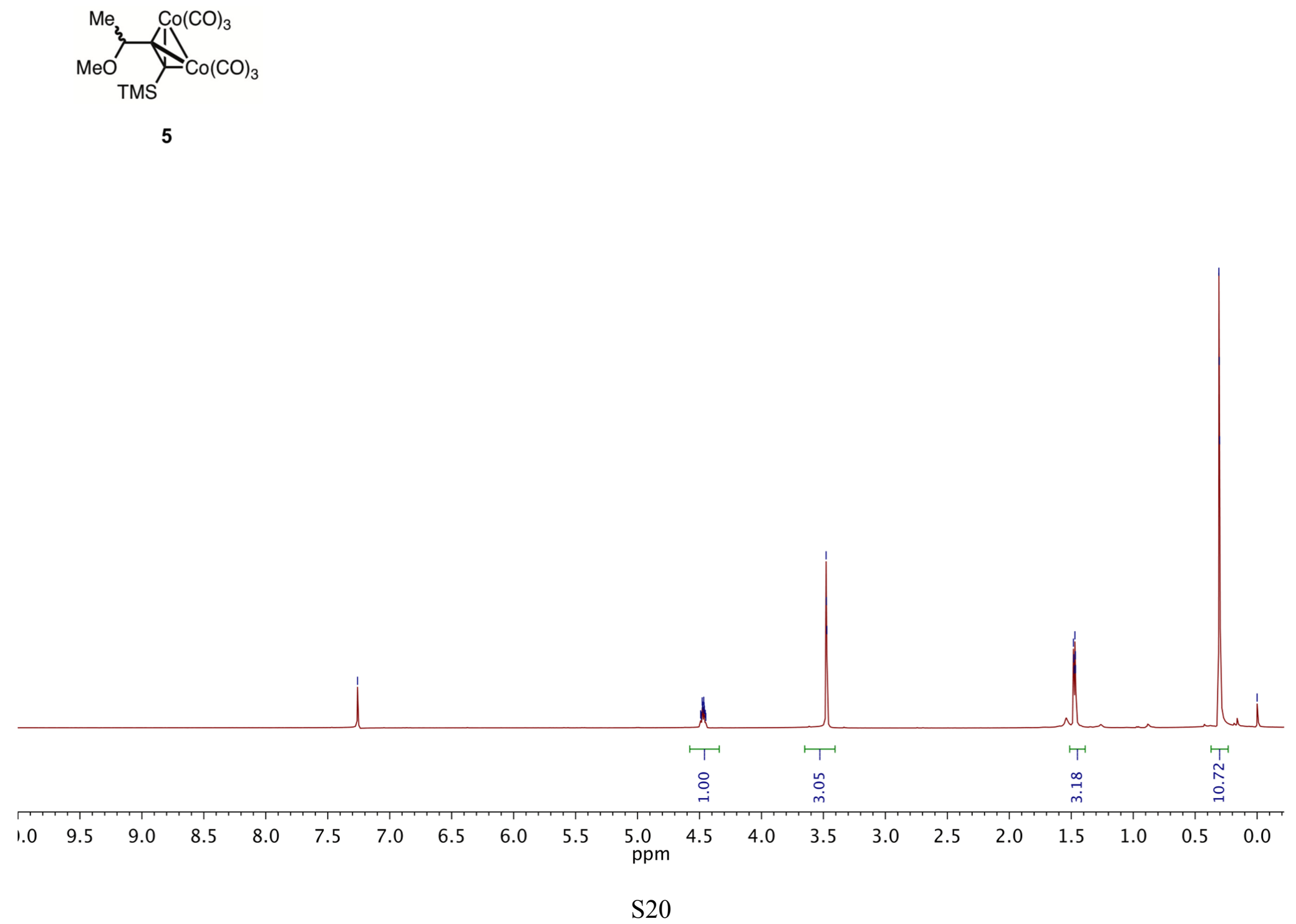
${ }^{13} \mathrm{C}\left\{{ }^{1} \mathrm{H}\right\} \mathrm{NMR}\left(\mathrm{CDCl}_{3}, 125 \mathrm{MHz}\right)$

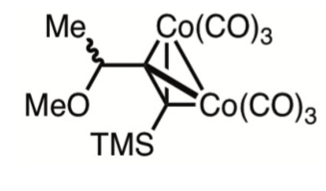

5

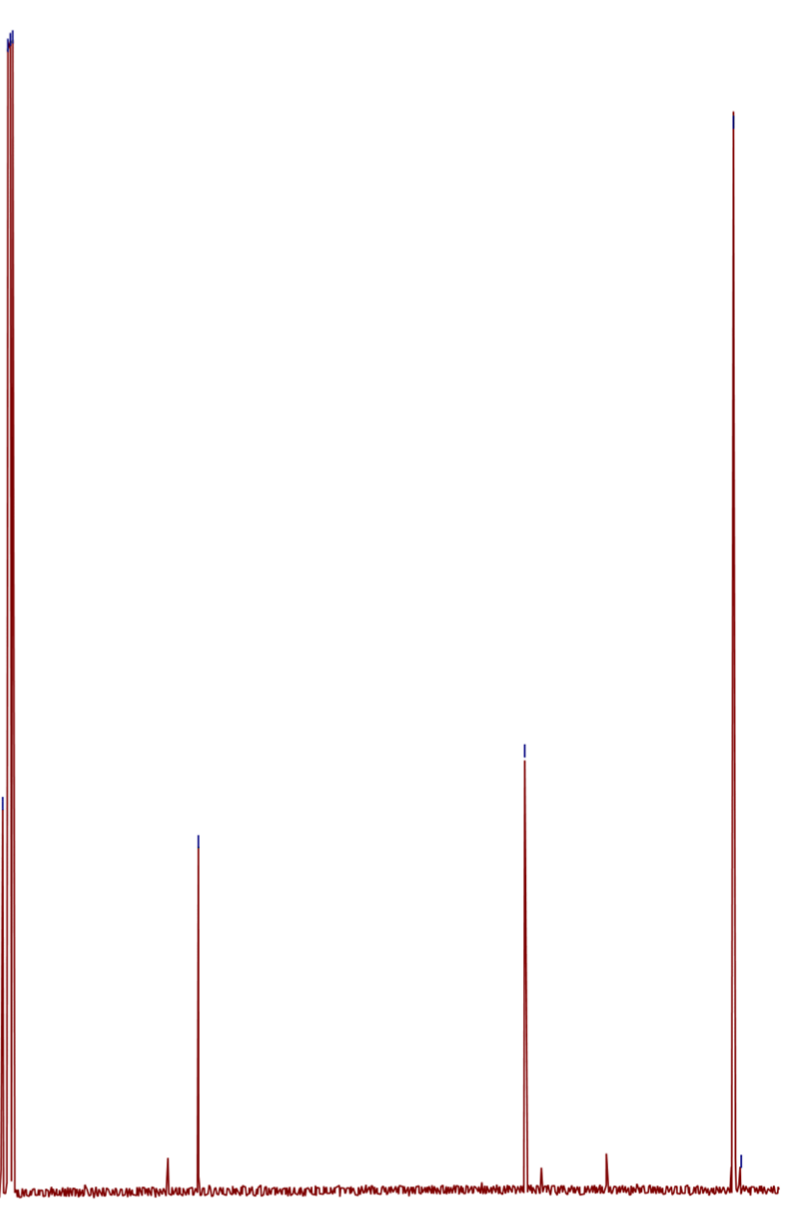

$\begin{array}{lllllllllll}10 & 200 & 190 & 180 & 170 & 160 & 150 & 140 & 130 & 120 & 110\end{array}$ ppm 


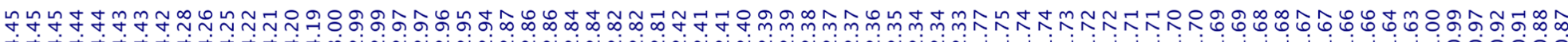

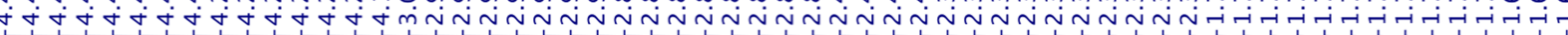

${ }^{1} \mathrm{H} \mathrm{NMR}\left(\mathrm{CDCl}_{3}, 500 \mathrm{MHz}\right)$
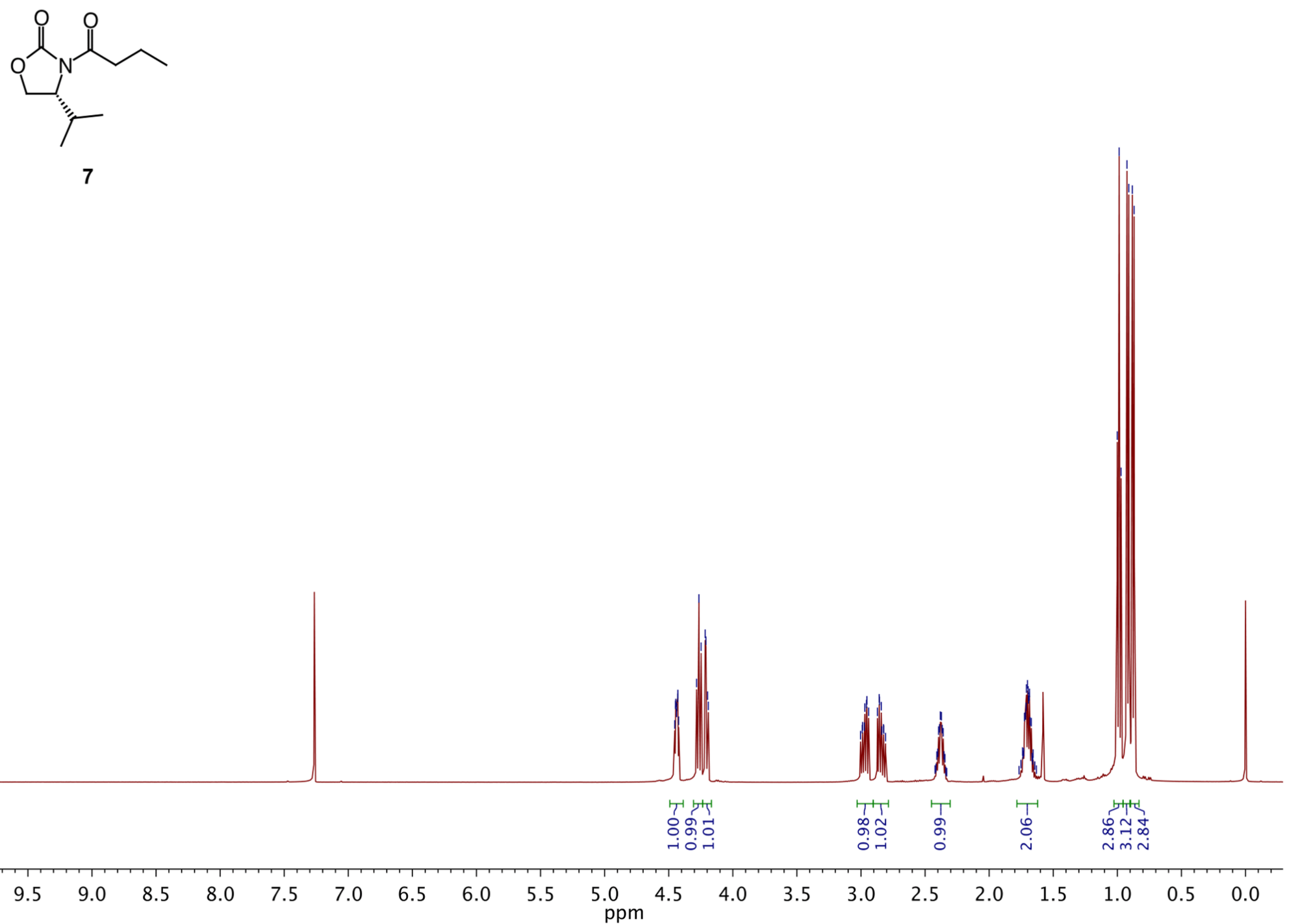


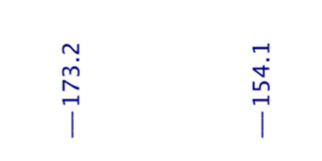

${ }^{13} \mathrm{C}\left\{{ }^{1} \mathrm{H}\right\} \mathrm{NMR}\left(\mathrm{CDCl}_{3}, 125 \mathrm{MHz}\right)$

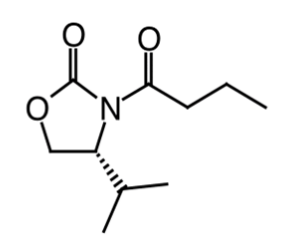

7

mimum whum

\begin{tabular}{lllllllllllllllllllll}
\hline 0 & 190 & 180 & 170 & 160 & 150 & 140 & 130 & 120 & 110 & $\underset{\mathrm{ppm}}{100}$ & 90 & 80 & 70 & 60 & 50 & 40 & 30 & 20 & 10 & 0
\end{tabular}




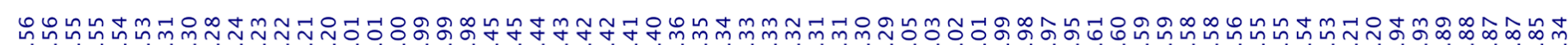

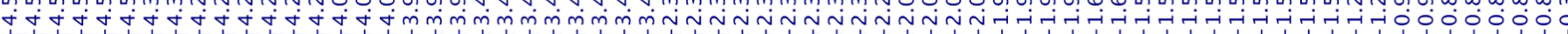
${ }^{1} \mathrm{H} \mathrm{NMR}\left(\mathrm{CDCl}_{3}, 500 \mathrm{MHz}\right)$
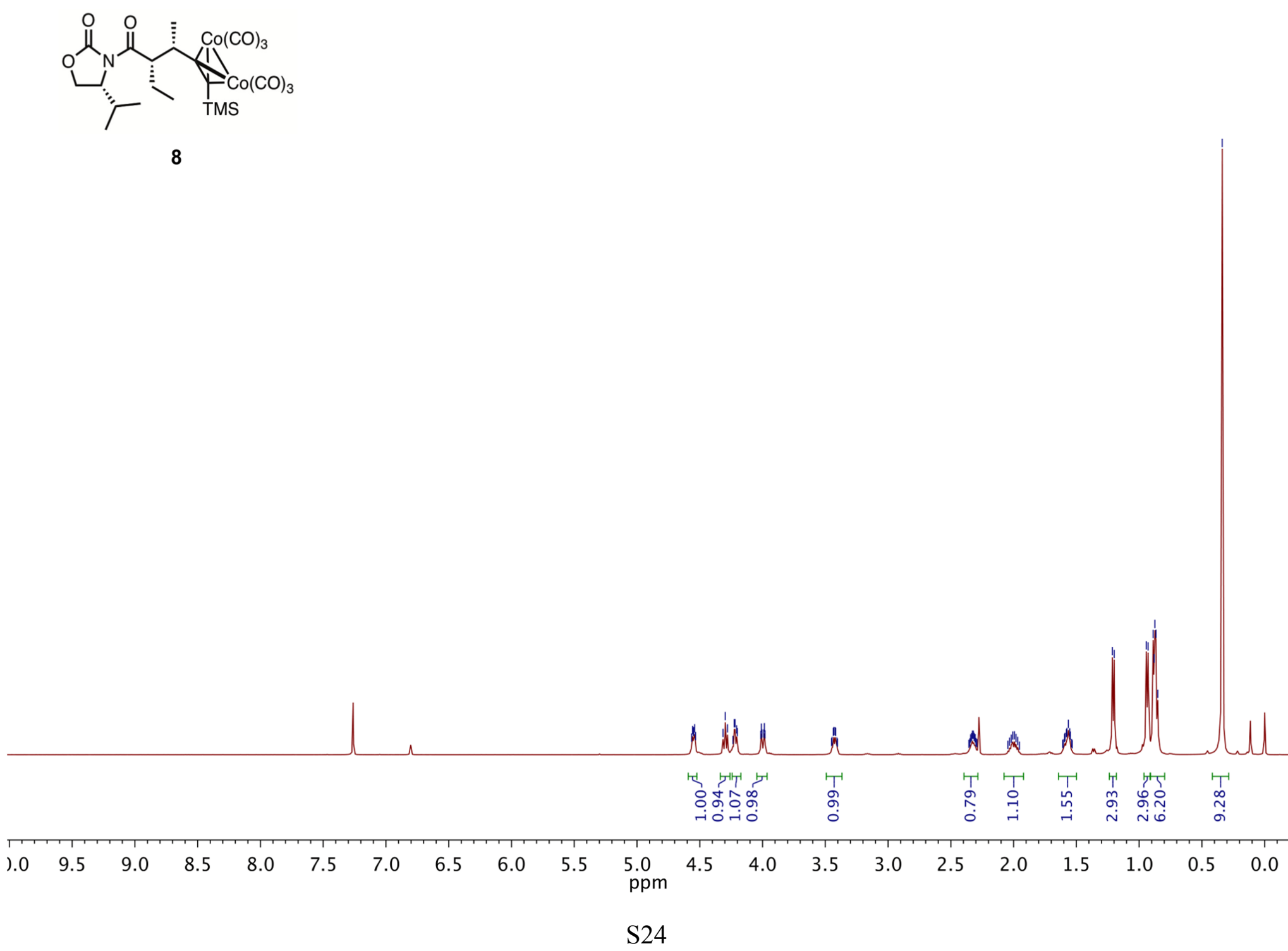


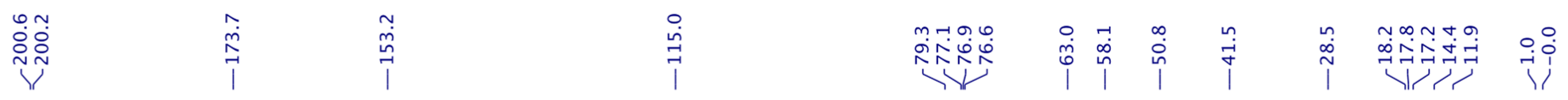

${ }^{13} \mathrm{C}\left\{{ }^{1} \mathrm{H}\right\} \mathrm{NMR}\left(\mathrm{CDCl}_{3}, 125 \mathrm{MHz}\right)$
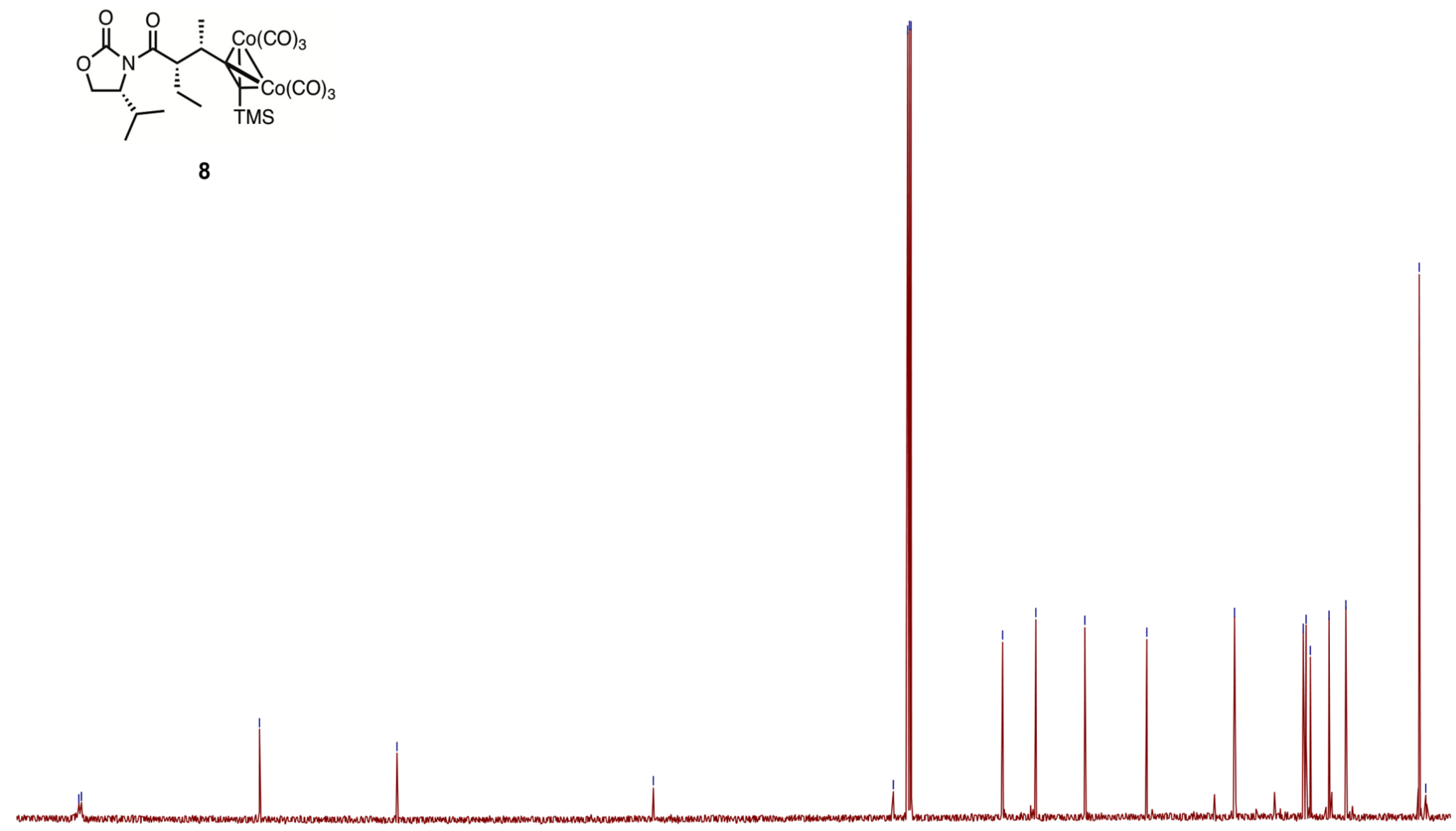

$\begin{array}{lllllllllllllllllllll}200 & 190 & 180 & 170 & 160 & 150 & 140 & 130 & 120 & 110 \begin{array}{c}100 \\ \mathrm{ppm}\end{array} & 90 & 80 & 70 & 60 & 50 & 40 & 30 & 20 & 10 & 0\end{array}$ 


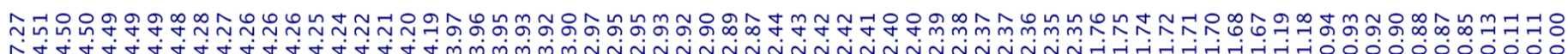

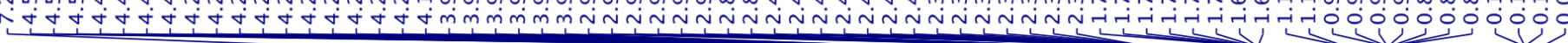

${ }^{1} \mathrm{H} \mathrm{NMR}\left(\mathrm{CDCl}_{3}, 500 \mathrm{MHz}\right)$
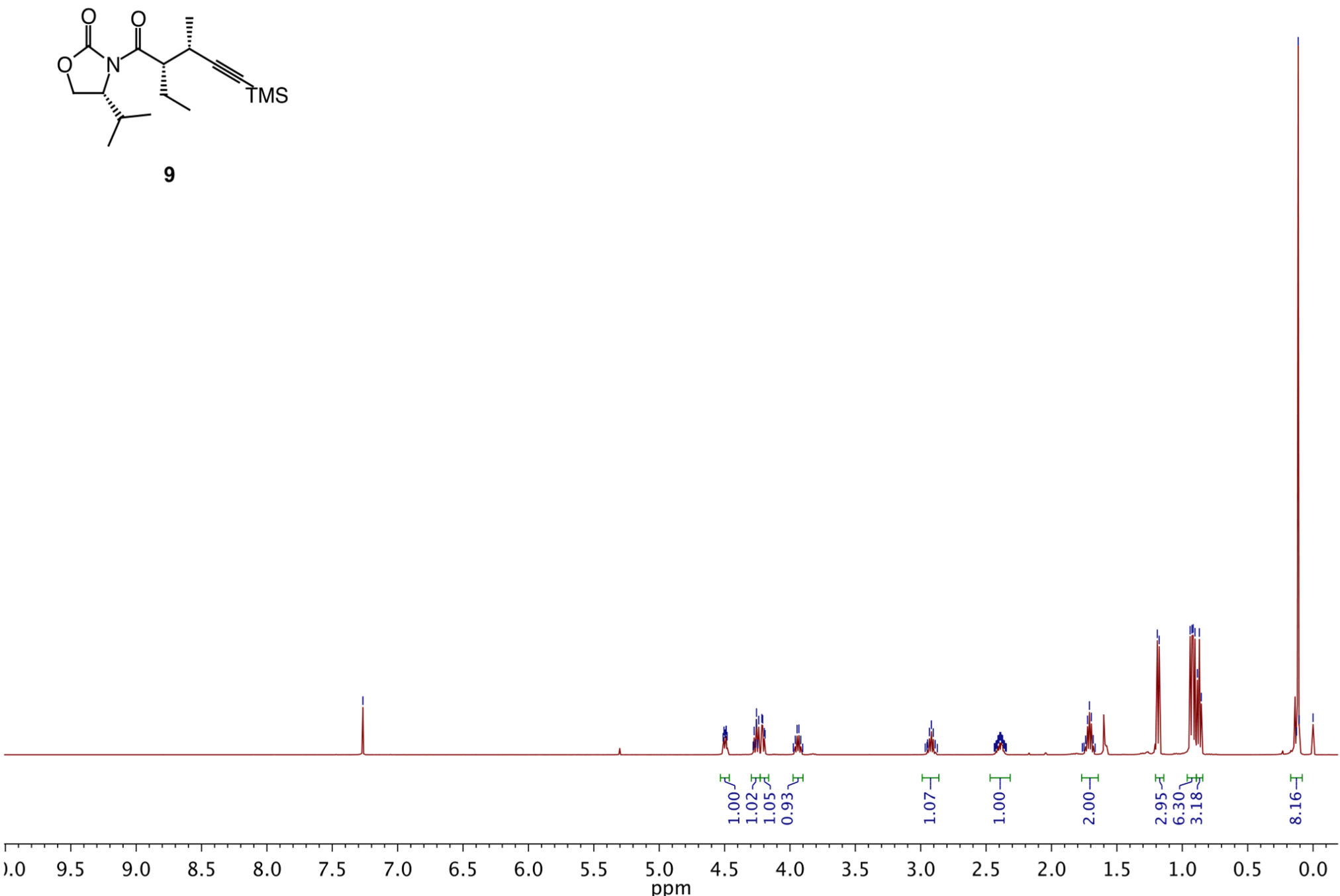


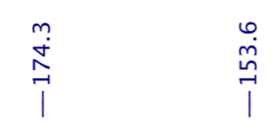
市

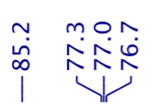

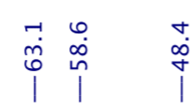

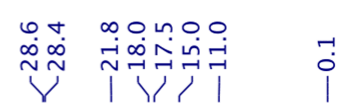

${ }^{13} \mathrm{C}\left\{{ }^{1} \mathrm{H}\right\} \operatorname{NMR}\left(\mathrm{CDCl}_{3}, 125 \mathrm{MHz}\right)$
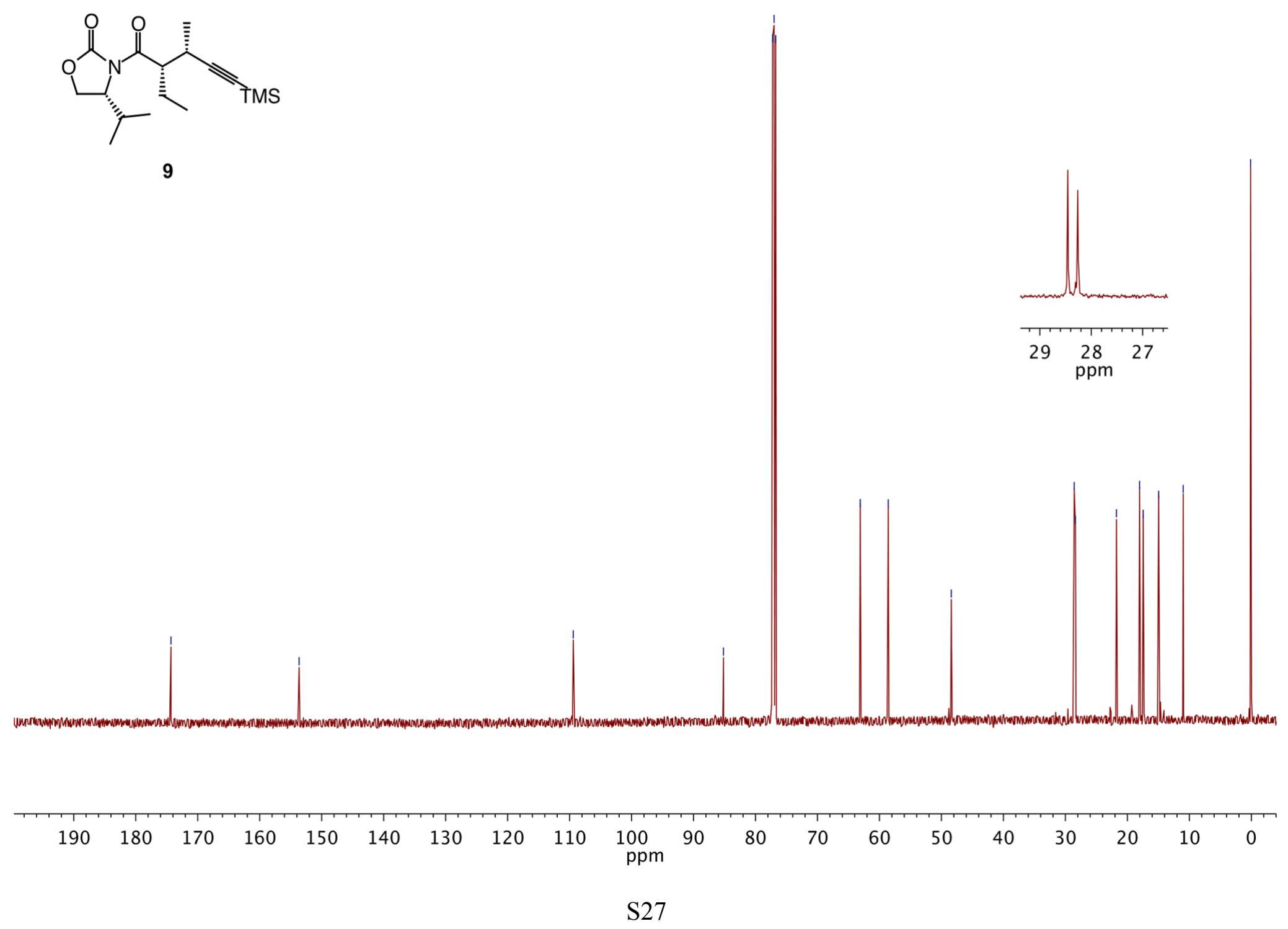
${ }^{1} \mathrm{H} \mathrm{NMR}\left(\mathrm{CDCl}_{3}, 500 \mathrm{MHz}\right)$
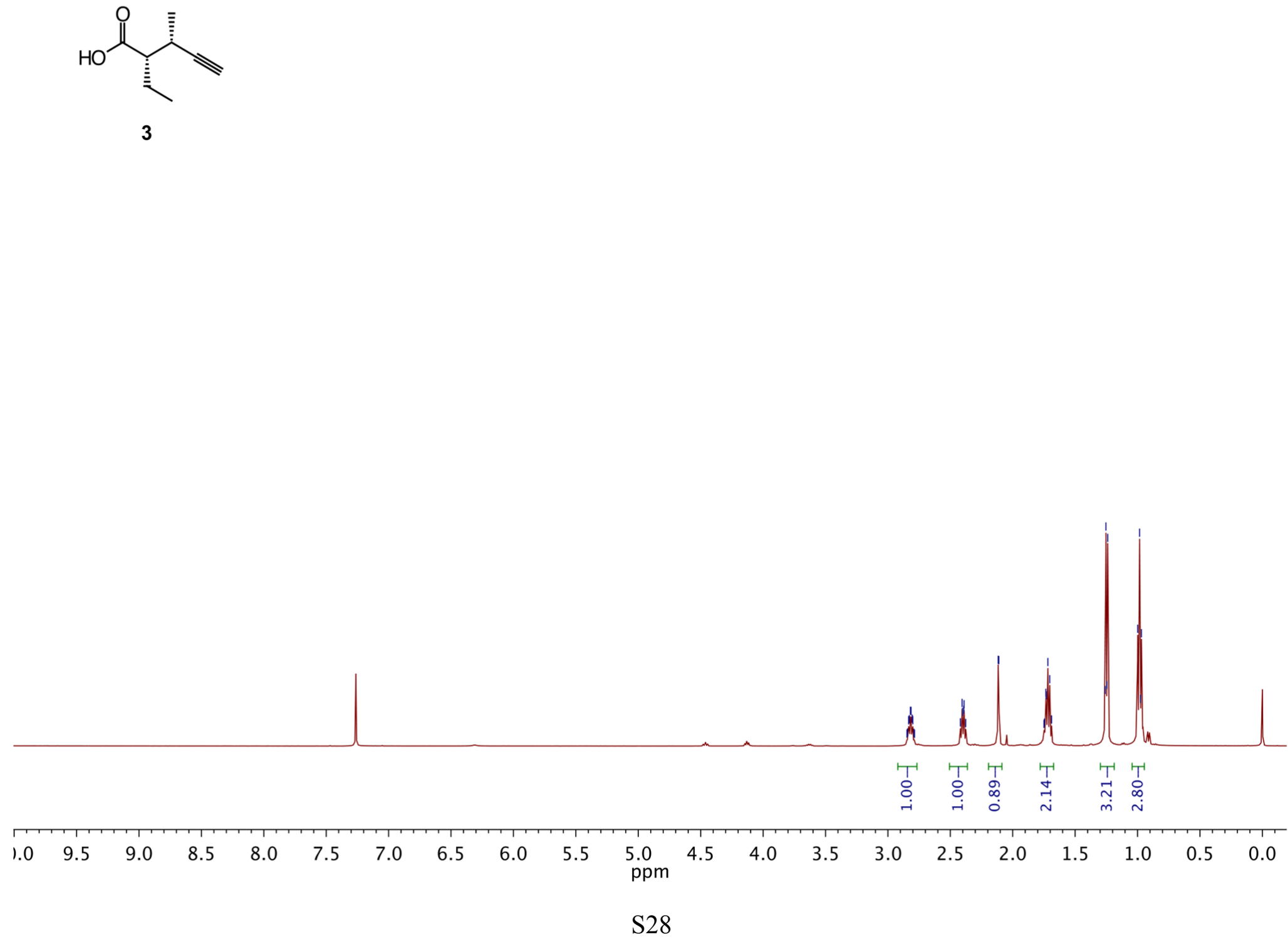
${ }^{13} \mathrm{C}\left\{{ }^{1} \mathrm{H}\right\} \mathrm{NMR}\left(\mathrm{CDCl}_{3}, 125 \mathrm{MHz}\right)$

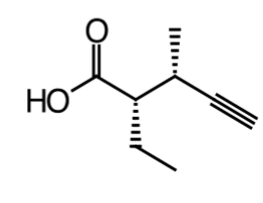

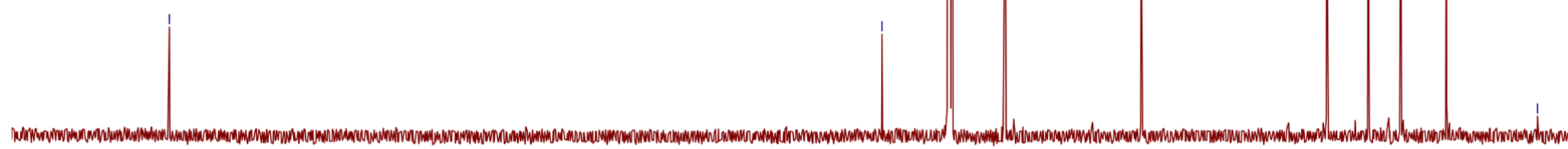

$\begin{array}{lllllllllllllllllllll}30 & 190 & 180 & 170 & 160 & 150 & 140 & 130 & 120 & 110 & \underset{\mathrm{ppm}}{100} & 90 & 80 & 70 & 60 & 50 & 40 & 30 & 20 & 10 & 0\end{array}$


${ }^{1} \mathrm{H} \mathrm{NMR}\left(\mathrm{CDCl}_{3}, 500 \mathrm{MHz}\right)$

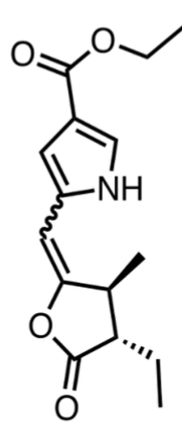

10

$E, Z$ mixture

contaminated with 2

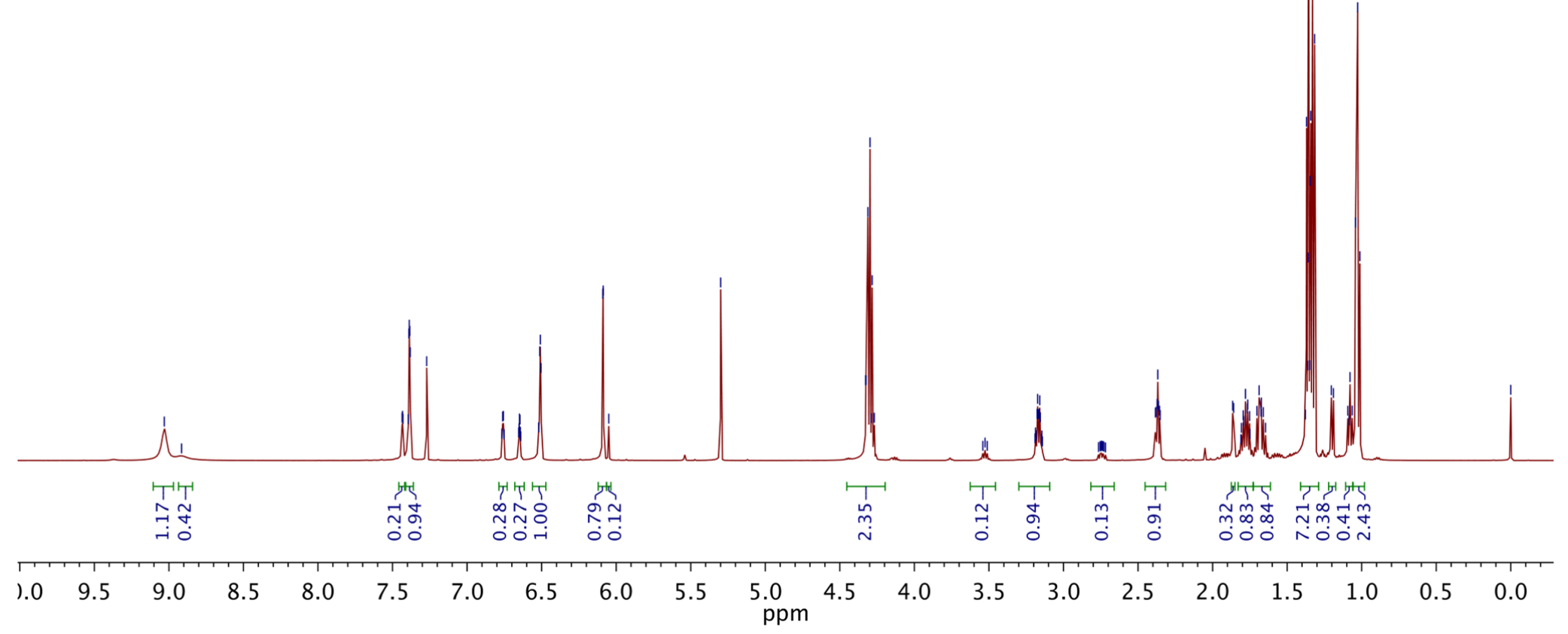




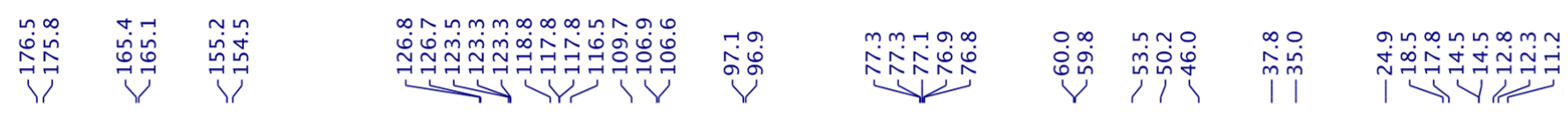

${ }^{13} \mathrm{C}\left\{{ }^{1} \mathrm{H}\right\} \operatorname{NMR}\left(\mathrm{CDCl}_{3}, 125 \mathrm{MHz}\right)$

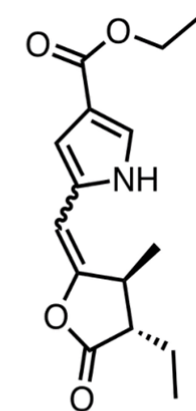

10

$E, Z$ mixture

contaminated with 2

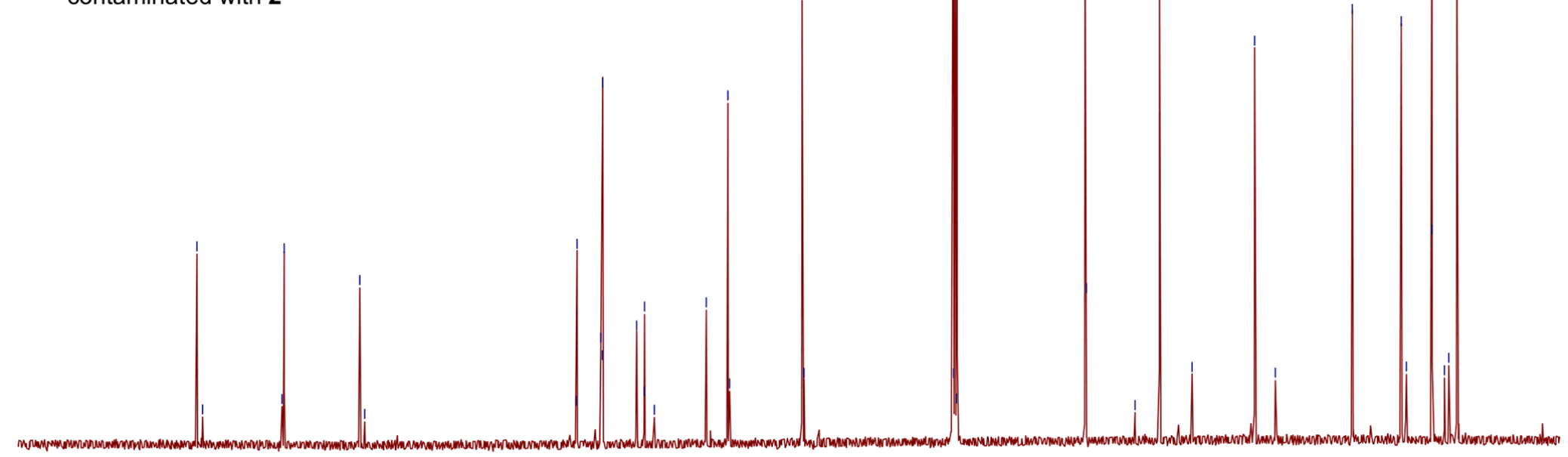

) 190

$180 \quad 170$

160

$150 \quad 140$

$130 \quad 120$

$110 \quad 100$

100
$\mathrm{ppm}$ 
ఈ웅 m

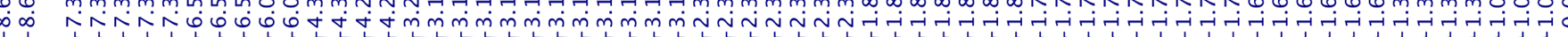

${ }^{1} \mathrm{H} \mathrm{NMR}\left(\mathrm{CDCl}_{3}, 500 \mathrm{MHz}\right)$
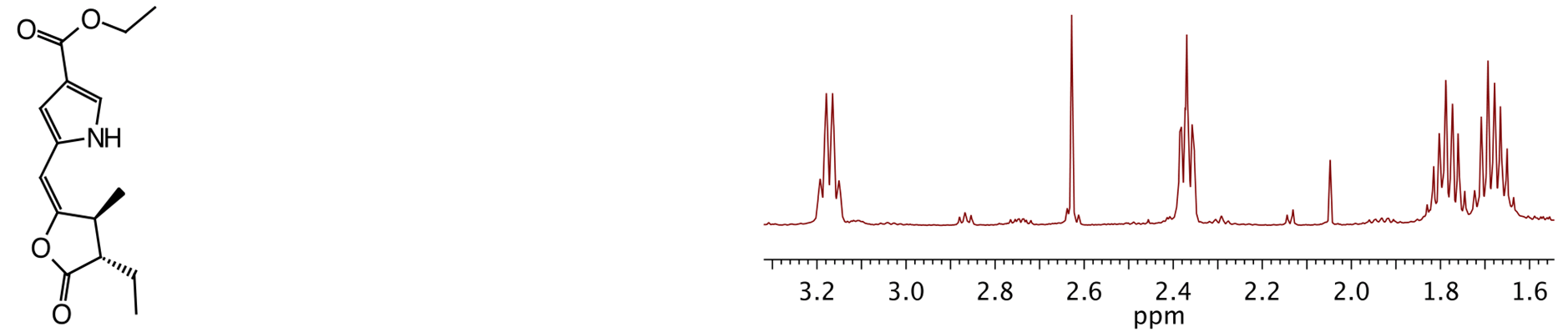

10

Small scale purification

by preparative TLC

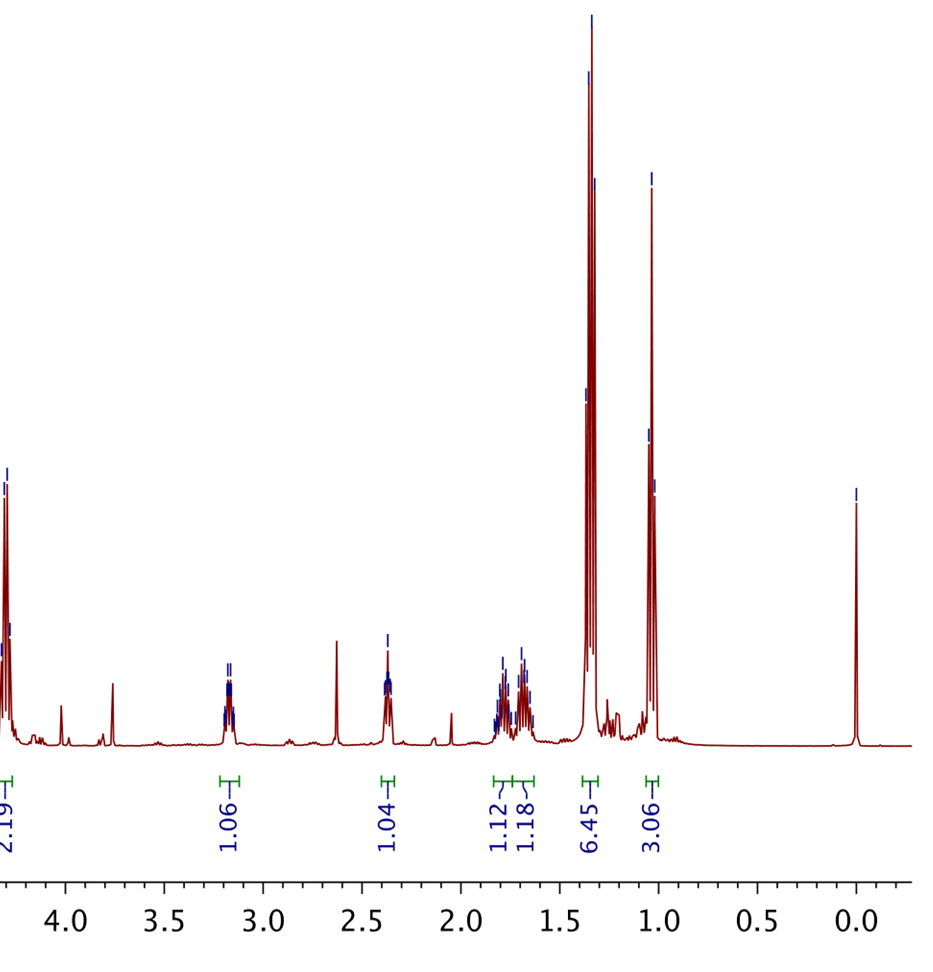




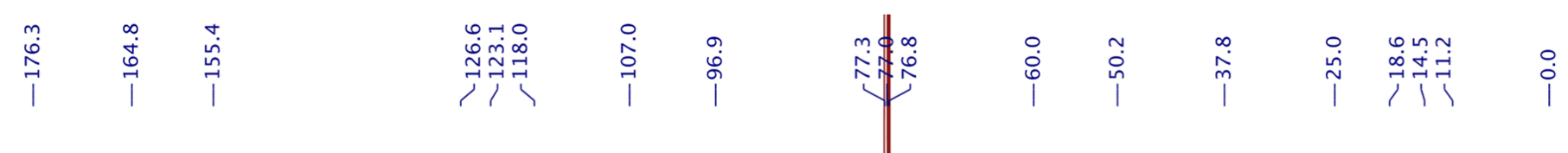

${ }^{13} \mathrm{C}\left\{{ }^{1} \mathrm{H}\right\} \operatorname{NMR}\left(\mathrm{CDCl}_{3}, 125 \mathrm{MHz}\right)$

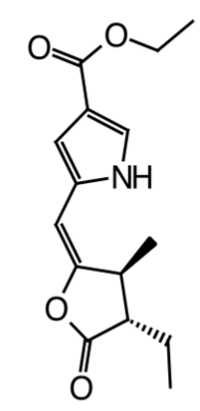

10

Small scale purification by preparative TLC

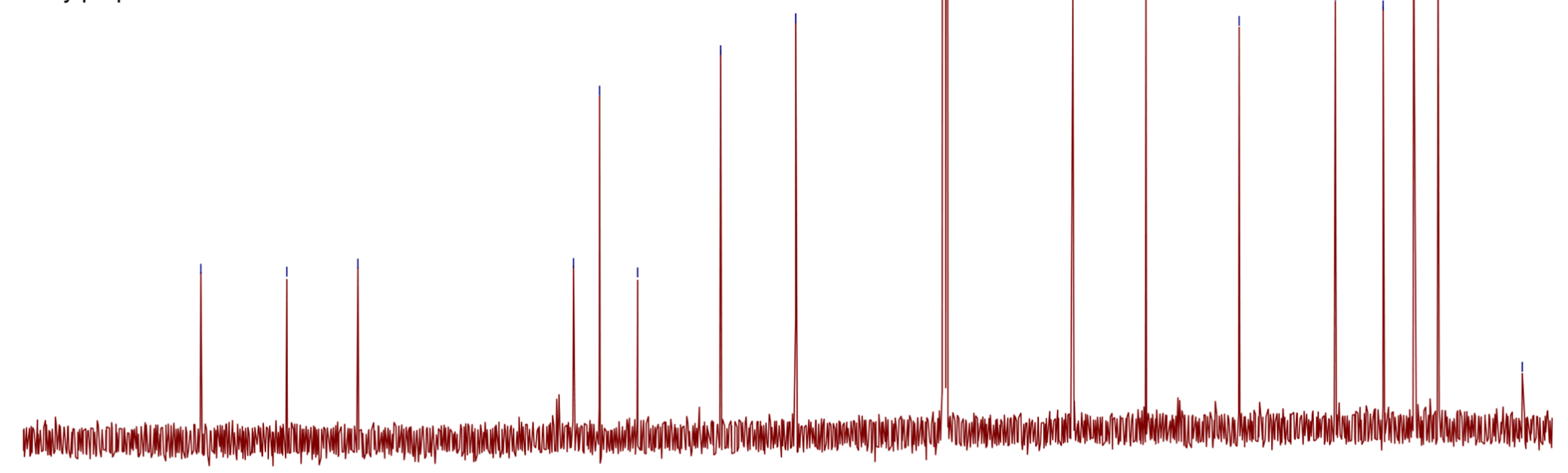

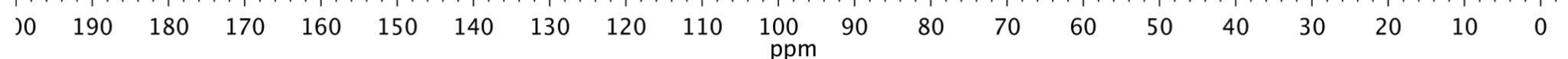


${ }^{1} \mathrm{H} \mathrm{NMR}\left(\mathrm{CDCl}_{3}, 500 \mathrm{MHz}\right)$
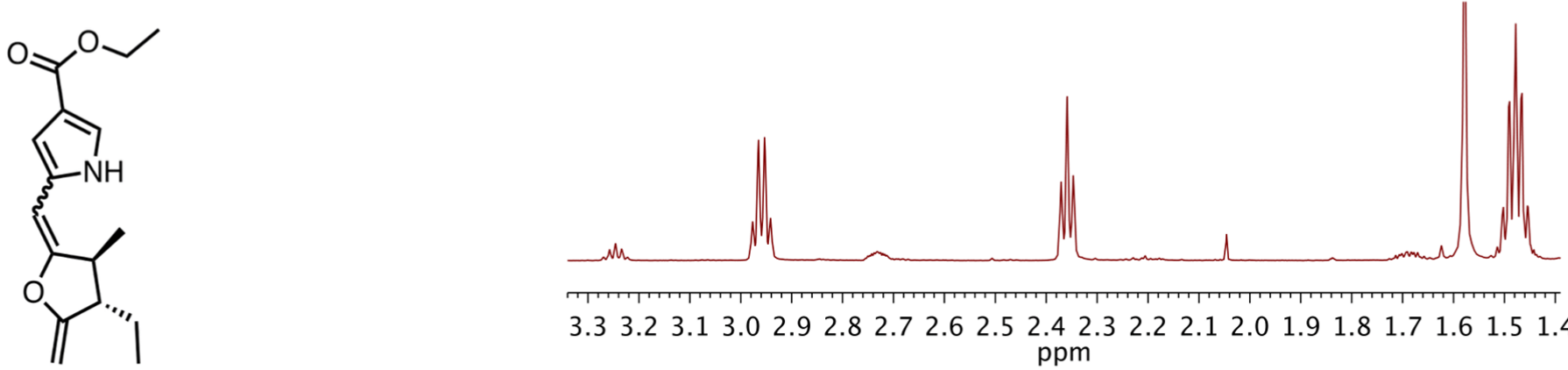

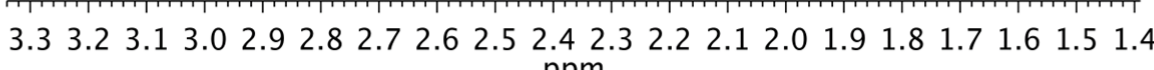

11

A mixture of $E / Z$ isomers

ppm

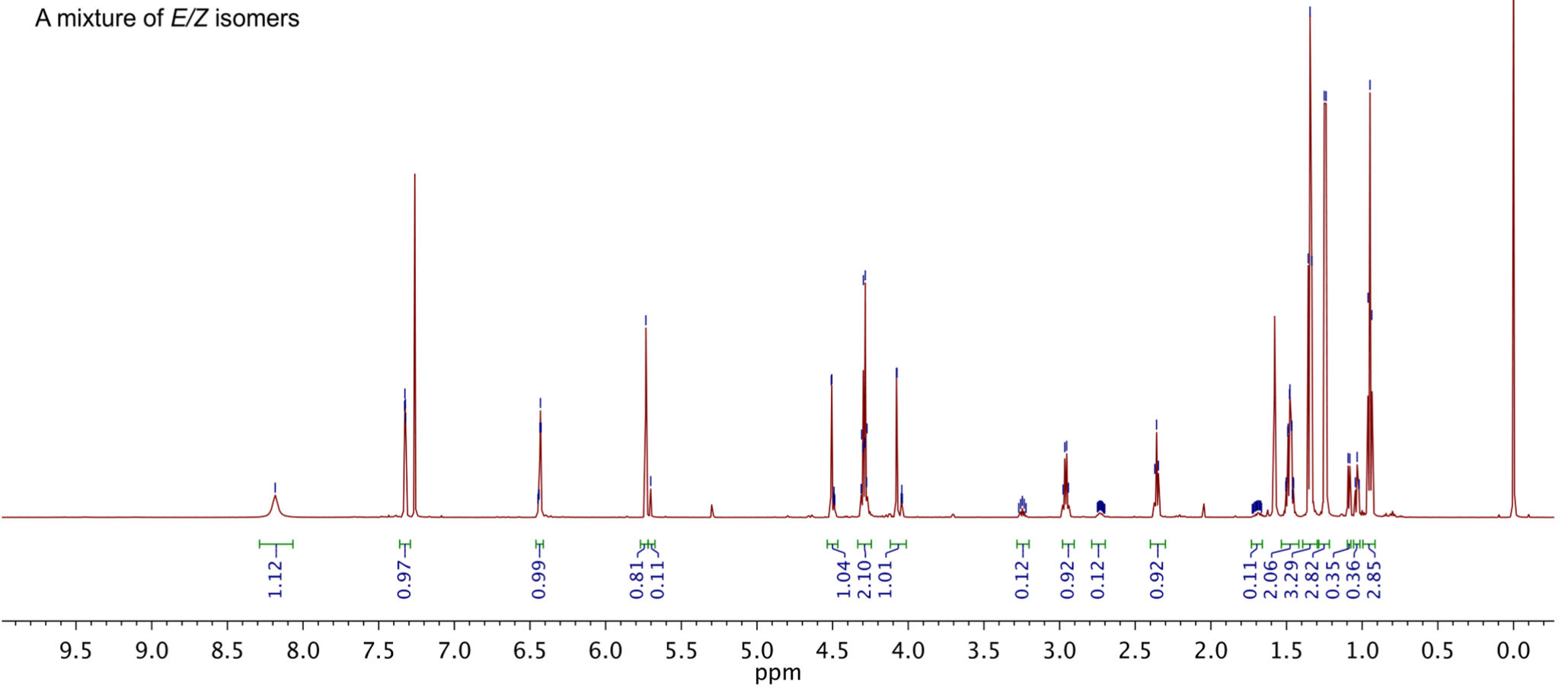




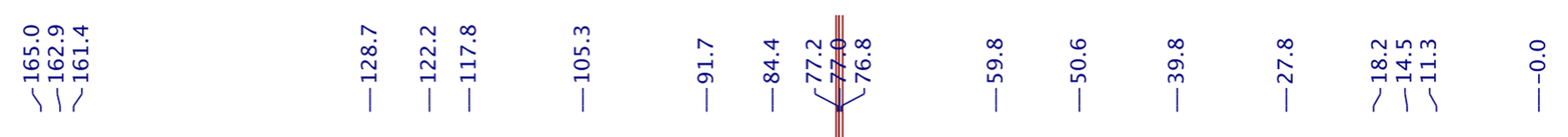

${ }^{13} \mathrm{C}\left\{{ }^{1} \mathrm{H}\right\}$ NMR $\left(\mathrm{CDCl}_{3}, 125 \mathrm{MHz}\right)$

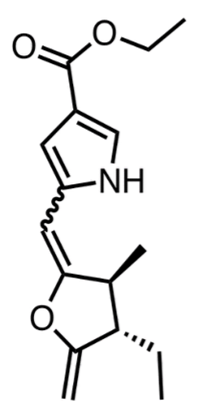

11

A mixture of $E / Z$ isomers

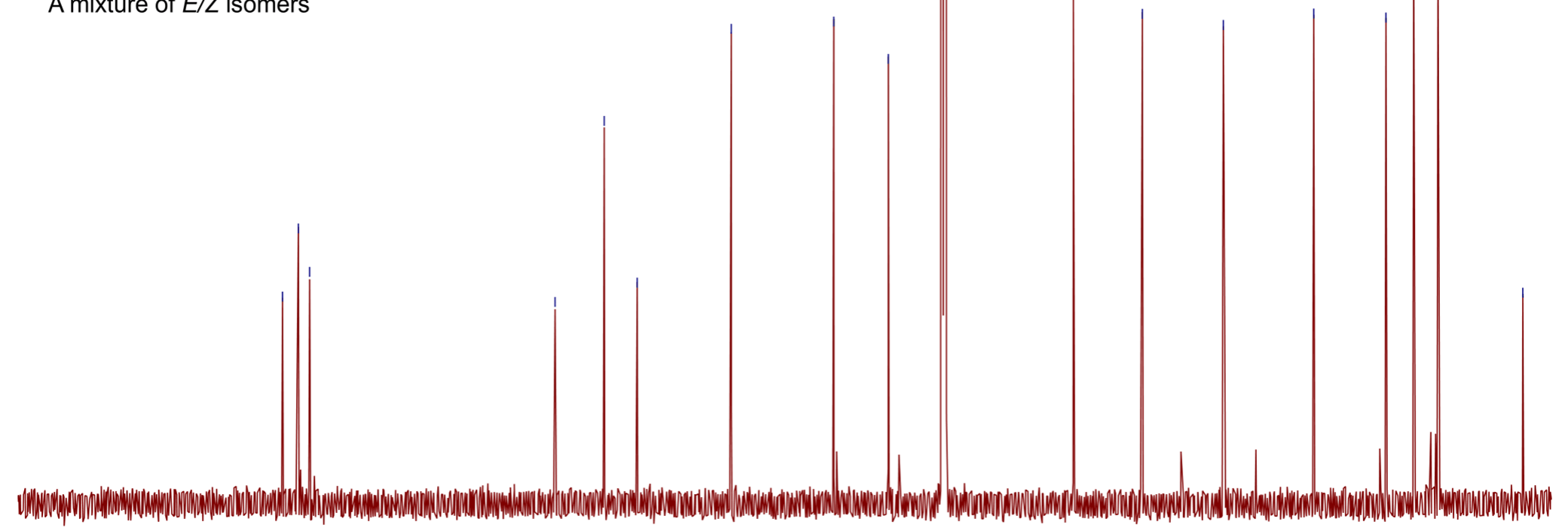

\begin{tabular}{lllllllllllllllllllll}
\hline 0 & 190 & 180 & 170 & 160 & 150 & 140 & 130 & 120 & 110 & $\underset{\mathrm{ppm}}{100}$ & 90 & 80 & 70 & 60 & 50 & 40 & 30 & 20 & 10 & 0
\end{tabular} 


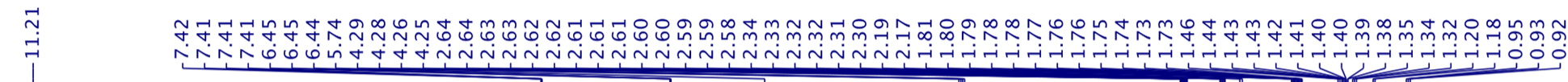

${ }^{1} \mathrm{H} \mathrm{NMR}\left(\mathrm{CDCl}_{3}, 500 \mathrm{MHz}\right)$

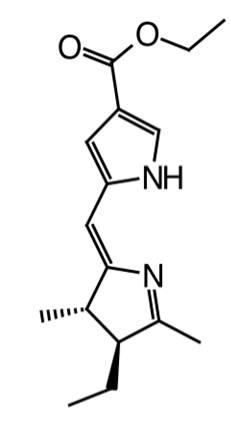

12

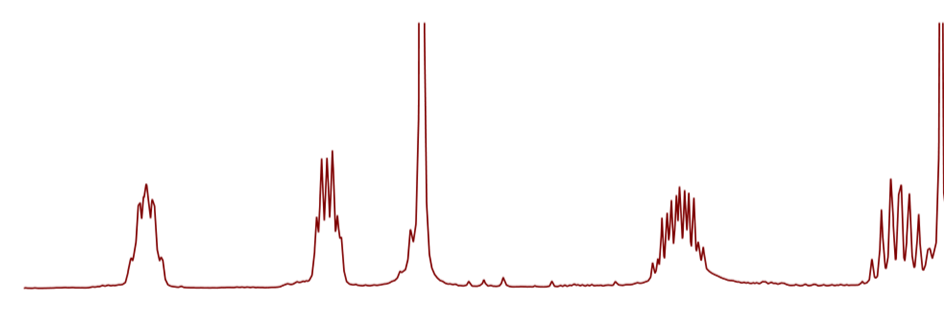

$\begin{array}{lllllllllllllll}2.8 & 2.7 & 2.6 & 2.5 & 2.4 & 2.3 & 2.2 & 2.1 & 2.0 & 1.9 & 1.8 & 1.7 & 1.6 & 1.5 & 1.4\end{array}$ $\mathrm{ppm}$

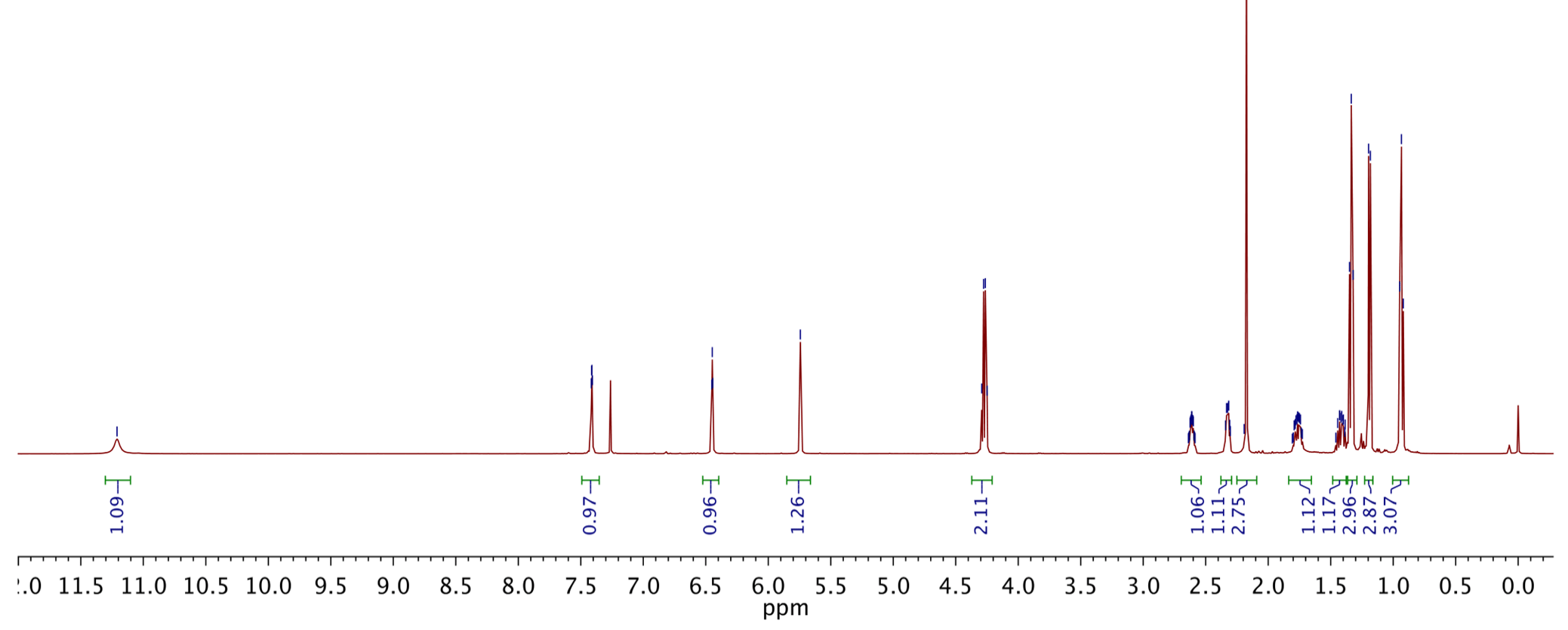




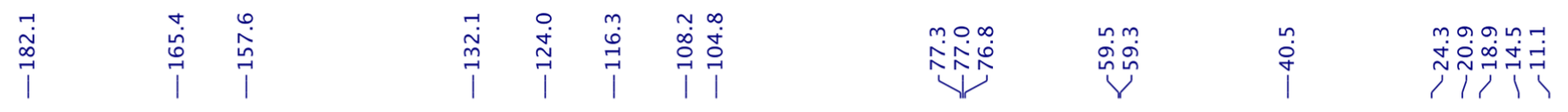

${ }^{13} \mathrm{C}\left\{{ }^{1} \mathrm{H}\right\} \mathrm{NMR}\left(\mathrm{CDCl}_{3}, 125 \mathrm{MHz}\right)$

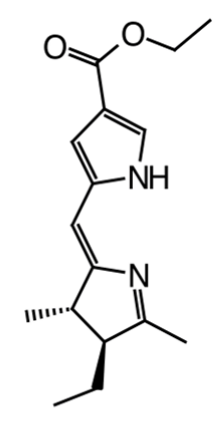

12

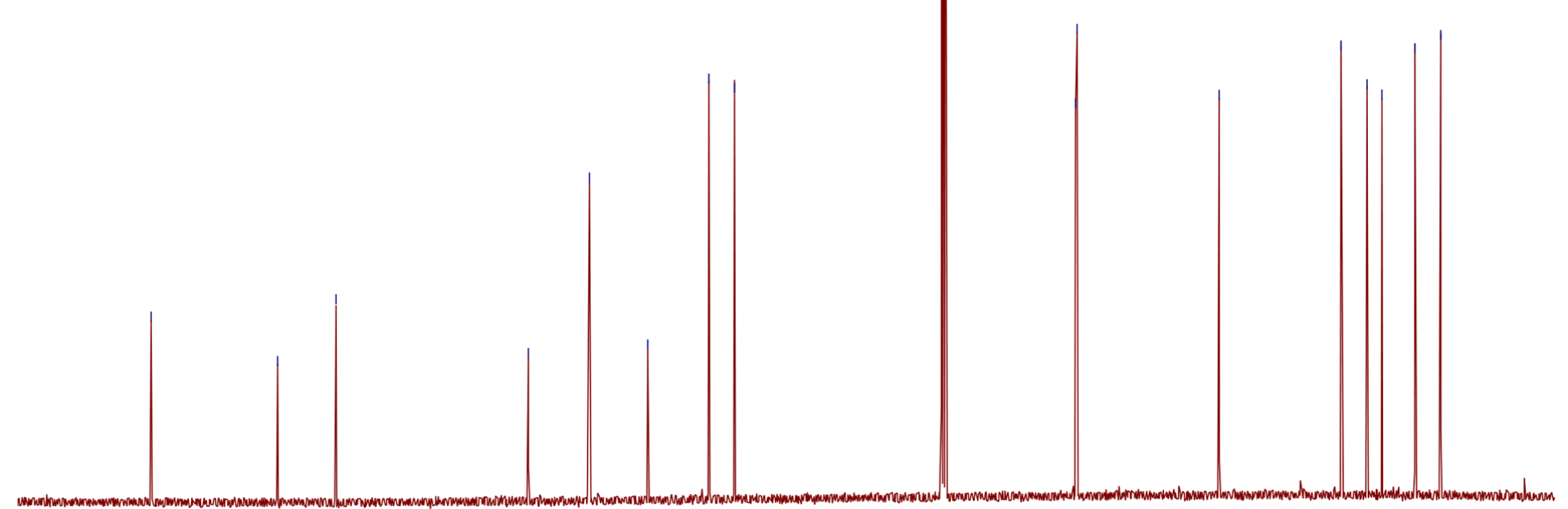

$190 \quad 180$

160

$140 \quad 130$

20110

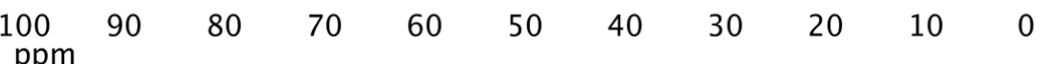




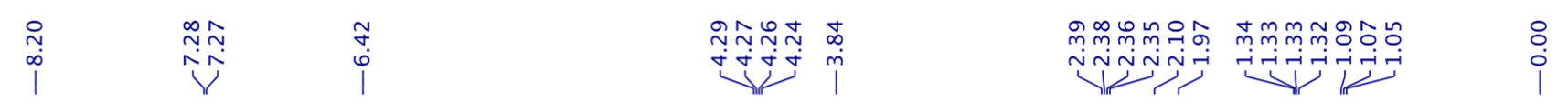

${ }^{1} \mathrm{H} \mathrm{NMR}\left(\mathrm{CDCl}_{3}, 500 \mathrm{MHz}\right)$
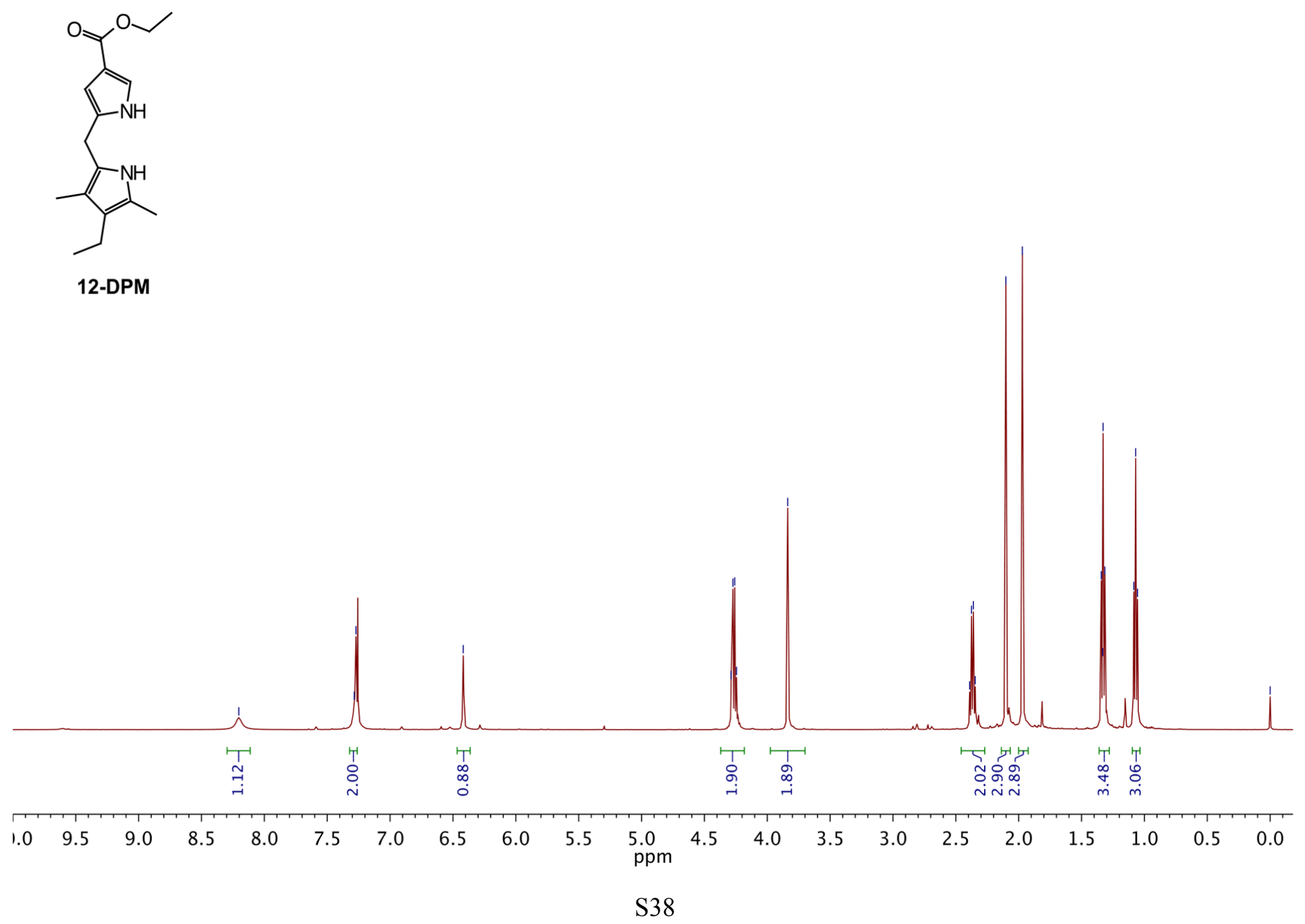


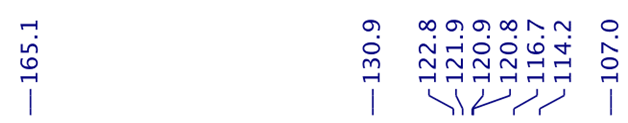

${ }^{13} \mathrm{C}\left\{{ }^{1} \mathrm{H}\right\} \mathrm{NMR}\left(\mathrm{CDCl}_{3}, 125 \mathrm{MHz}\right)$
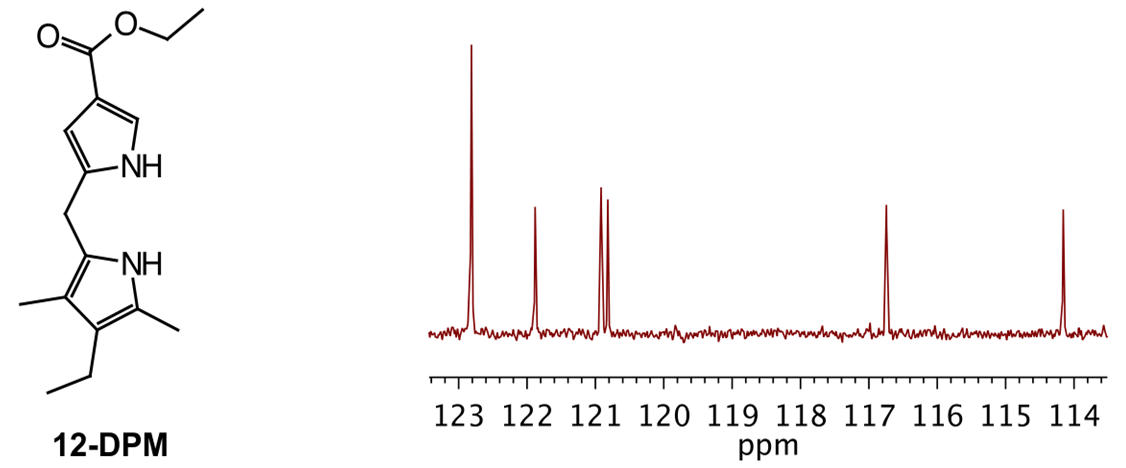

12-DPM

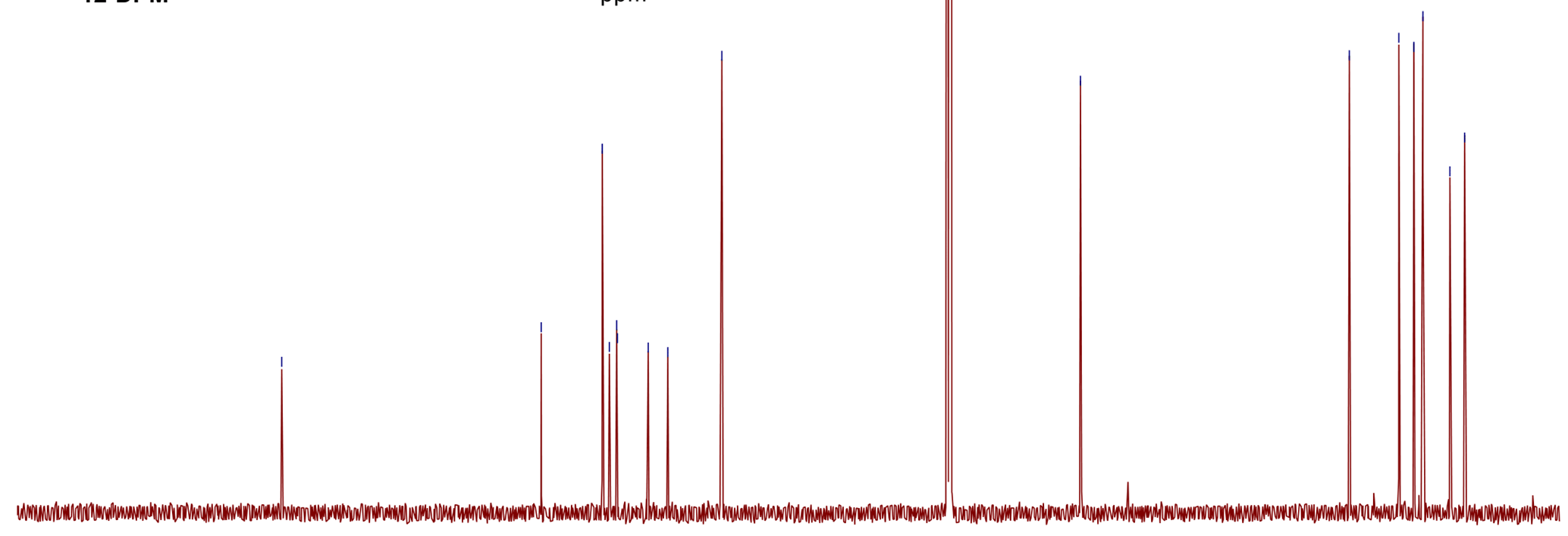

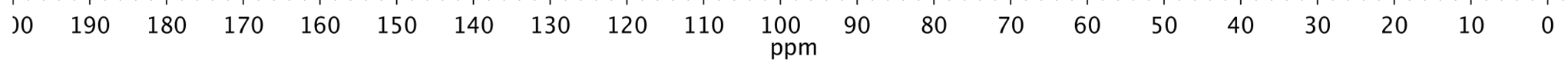




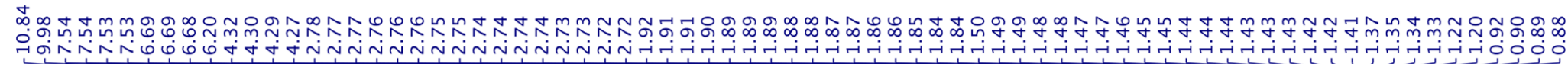

${ }^{1} \mathrm{H} \mathrm{NMR}\left(\mathrm{CDCl}_{3}, 500 \mathrm{MHz}\right)$

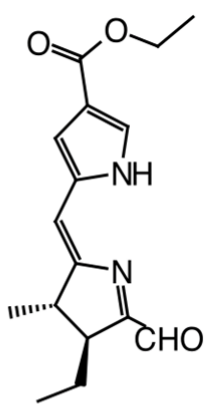

13
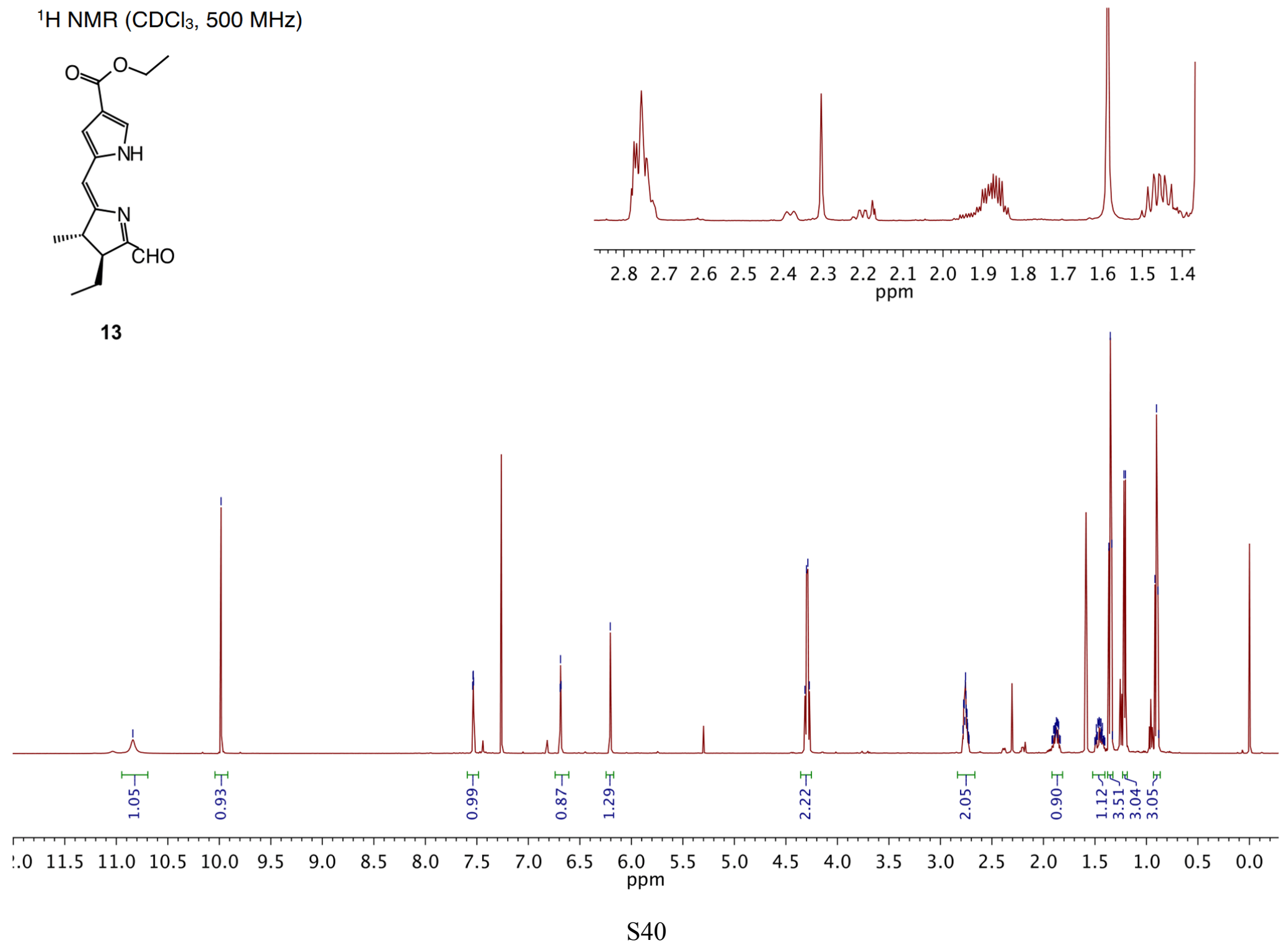
${ }^{13} \mathrm{C}\left\{{ }^{1} \mathrm{H}\right\} \mathrm{NMR}\left(\mathrm{CDCl}_{3}, 125 \mathrm{MHz}\right)$

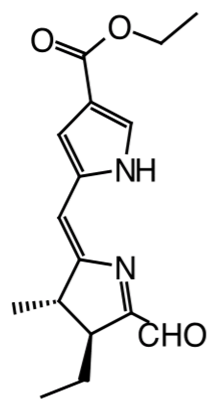

13

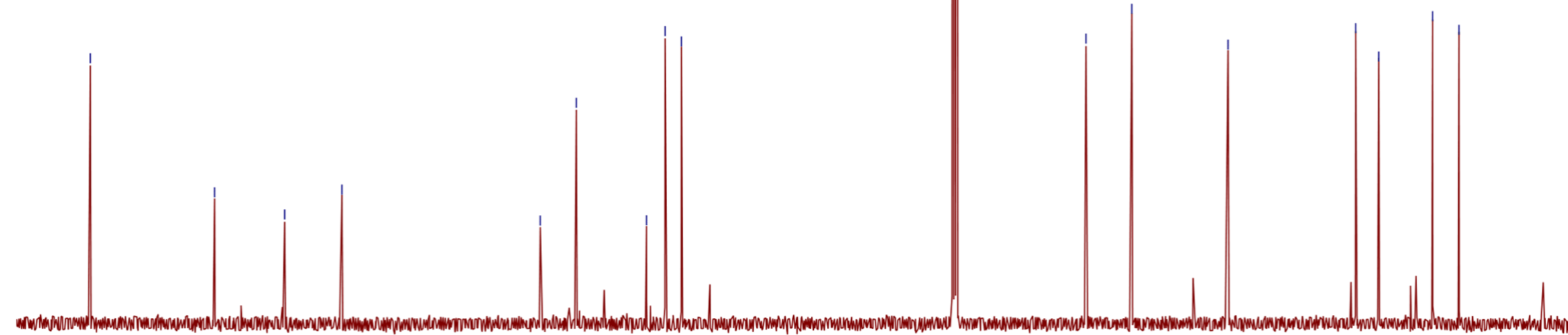

$\begin{array}{llllllllllllllllllll}190 & 180 & 170 & 160 & 150 & 140 & 130 & 120 & 110 & \begin{array}{c}100 \\ \mathrm{ppm}\end{array} & 90 & 80 & 70 & 60 & 50 & 40 & 30 & 20 & 10 & 0\end{array}$ 


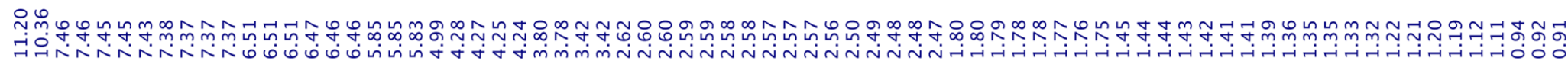

(1)

${ }^{1} \mathrm{H} \mathrm{NMR}\left(\mathrm{CDCl}_{3}, 500 \mathrm{MHz}\right)$
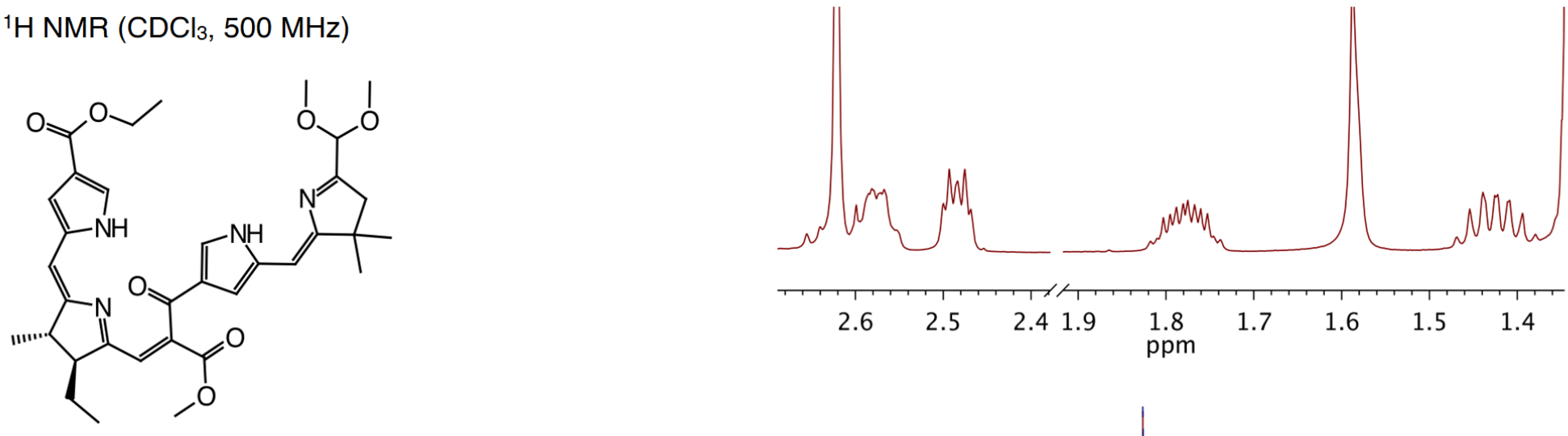

14-E

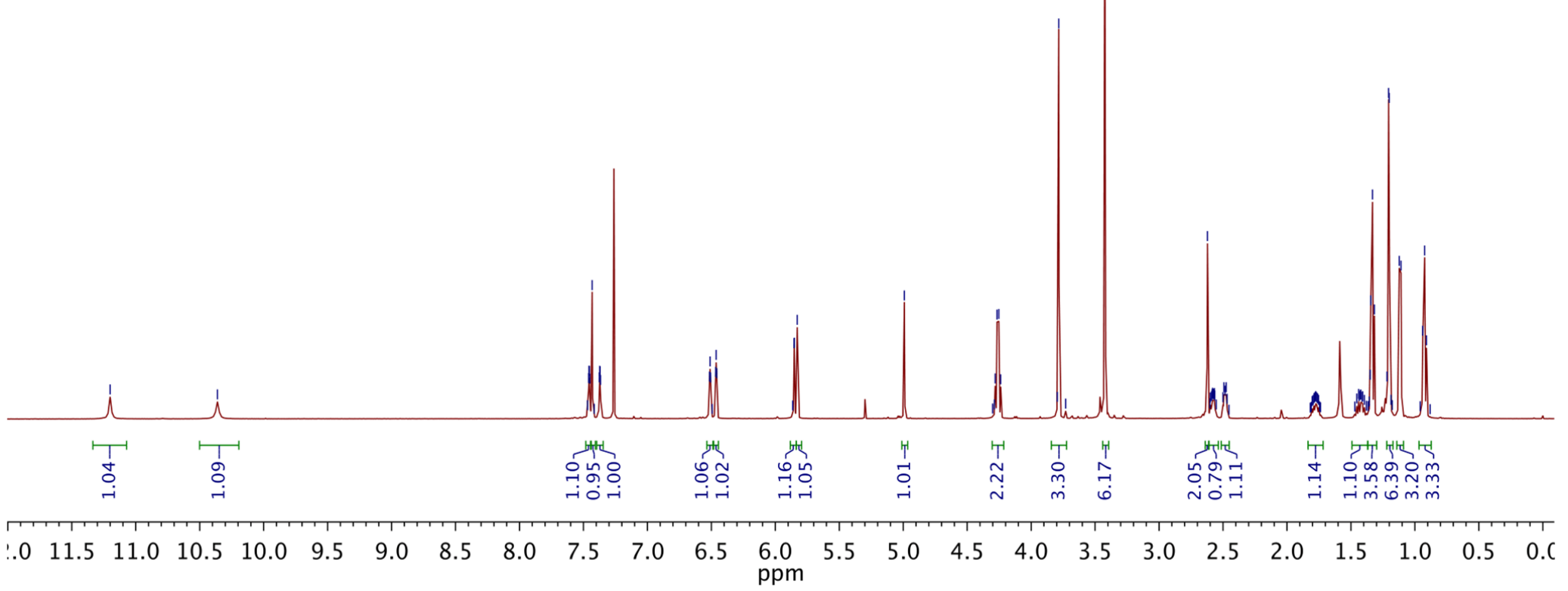




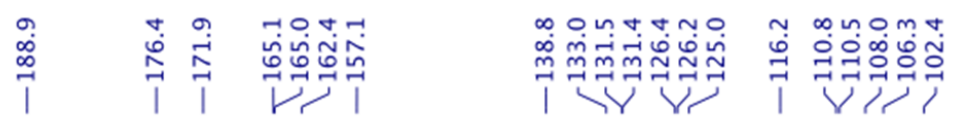

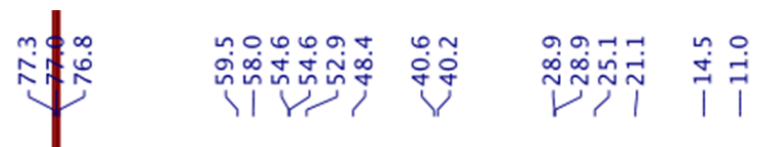

${ }^{13} \mathrm{C}\left\{{ }^{1} \mathrm{H}\right\} \mathrm{NMR}\left(\mathrm{CDCl}_{3}, 125 \mathrm{MHz}\right)$
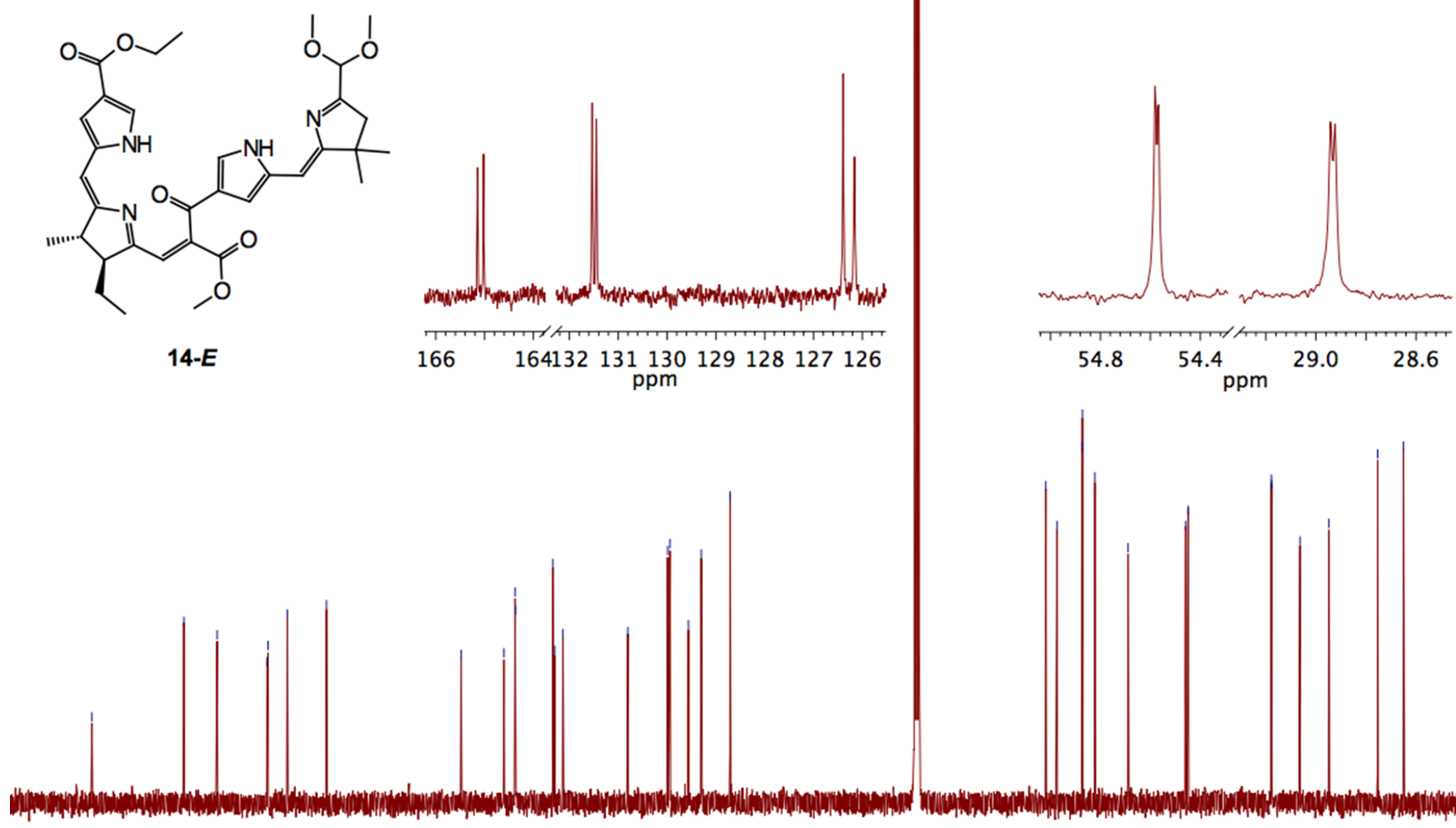

$\begin{array}{lllll}0 & 190 & 180 & 170 & 160\end{array}$

$50 \quad 140$

$130 \quad 120 \quad 110$

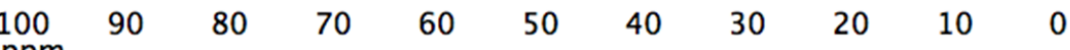




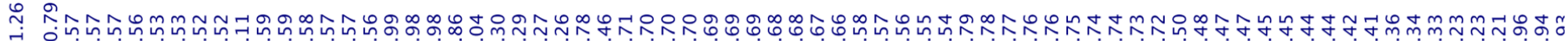

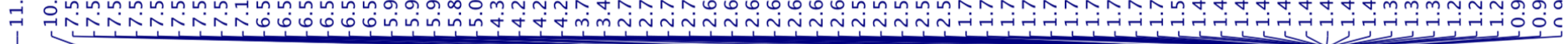

\section{${ }^{1} \mathrm{H} \mathrm{NMR}\left(\mathrm{CDCl}_{3}, 500 \mathrm{MHz}\right)$}
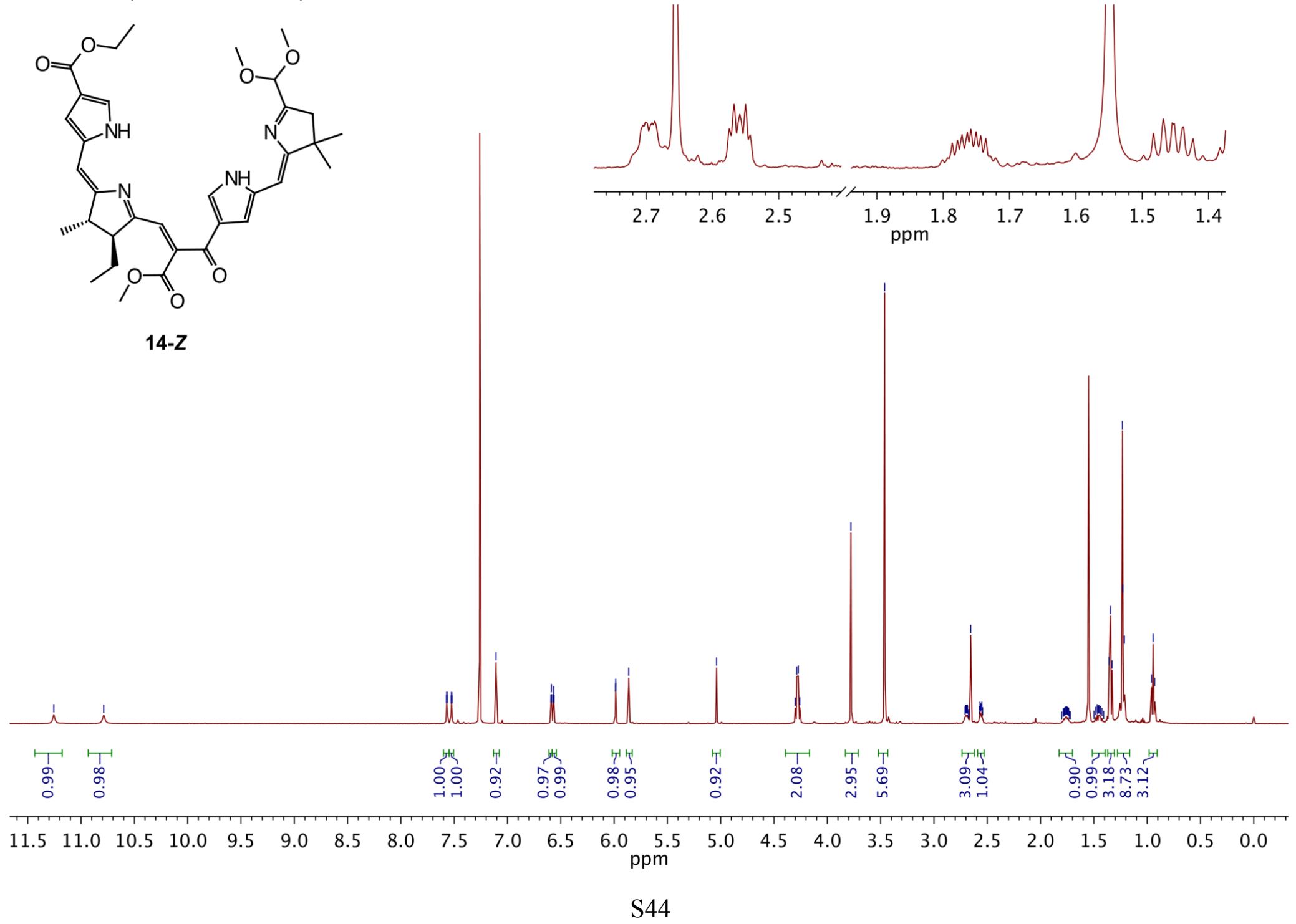


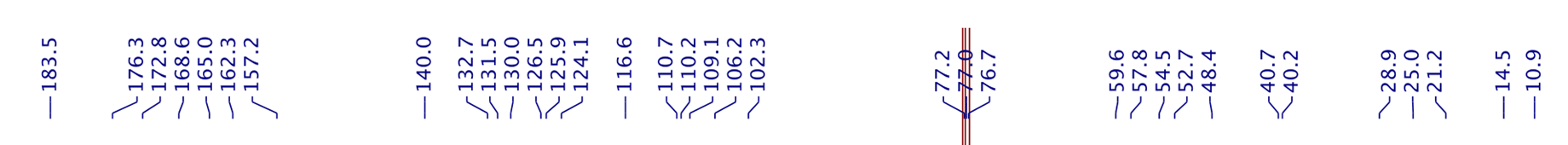

${ }^{13} \mathrm{C}\left\{{ }^{1} \mathrm{H}\right\} \mathrm{NMR}\left(\mathrm{CDCl}_{3}, 125 \mathrm{MHz}\right)$
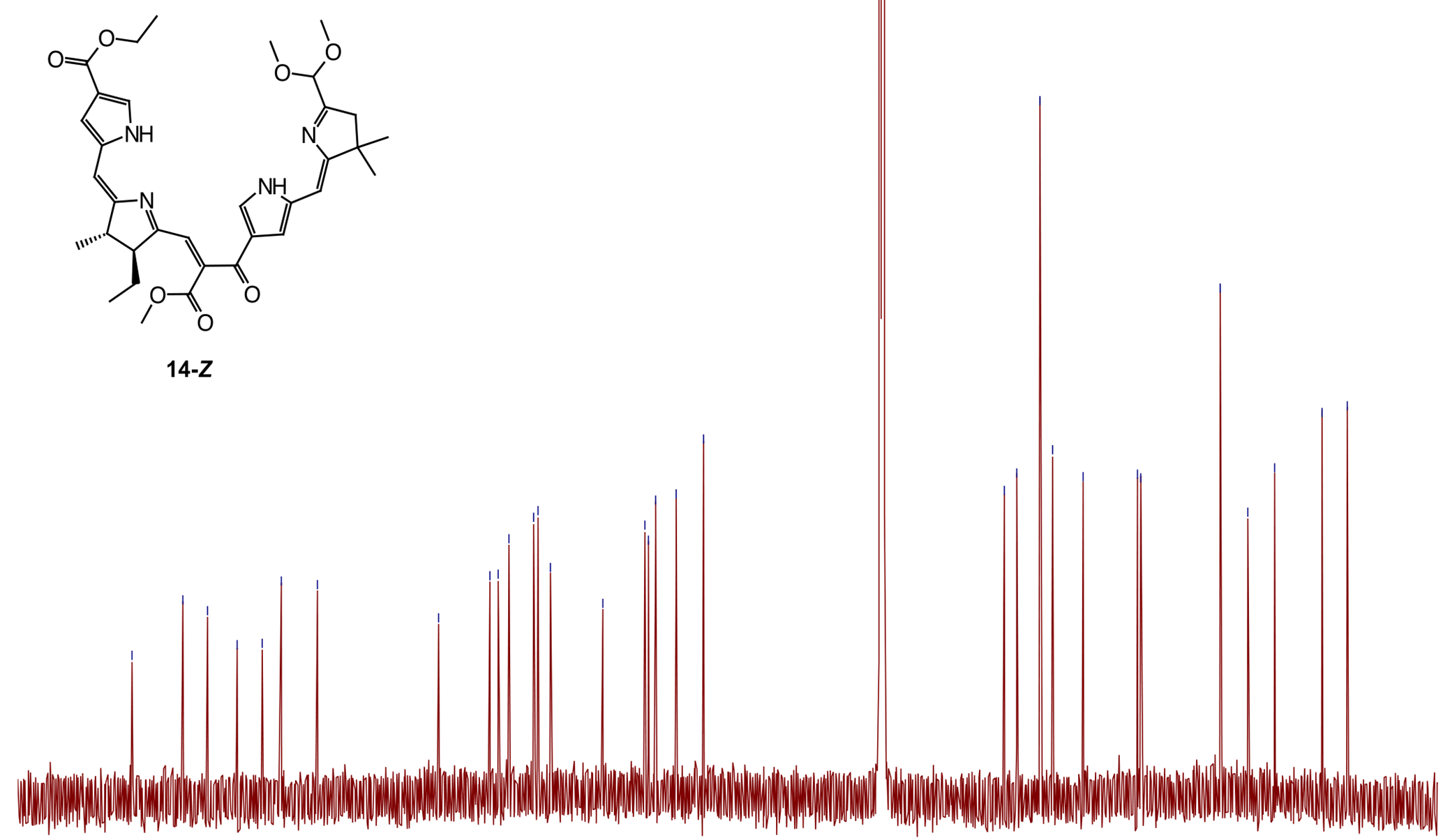

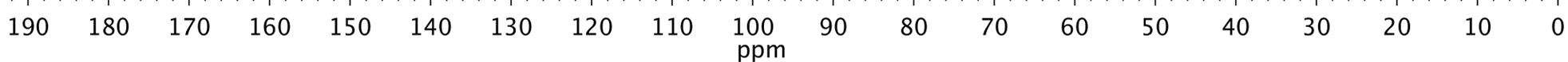




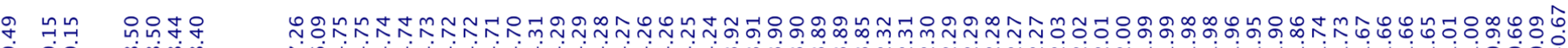

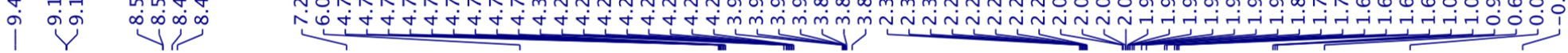

${ }^{1} \mathrm{H} \mathrm{NMR}\left(\mathrm{CDCl}_{3}, 500 \mathrm{MHz}\right)$
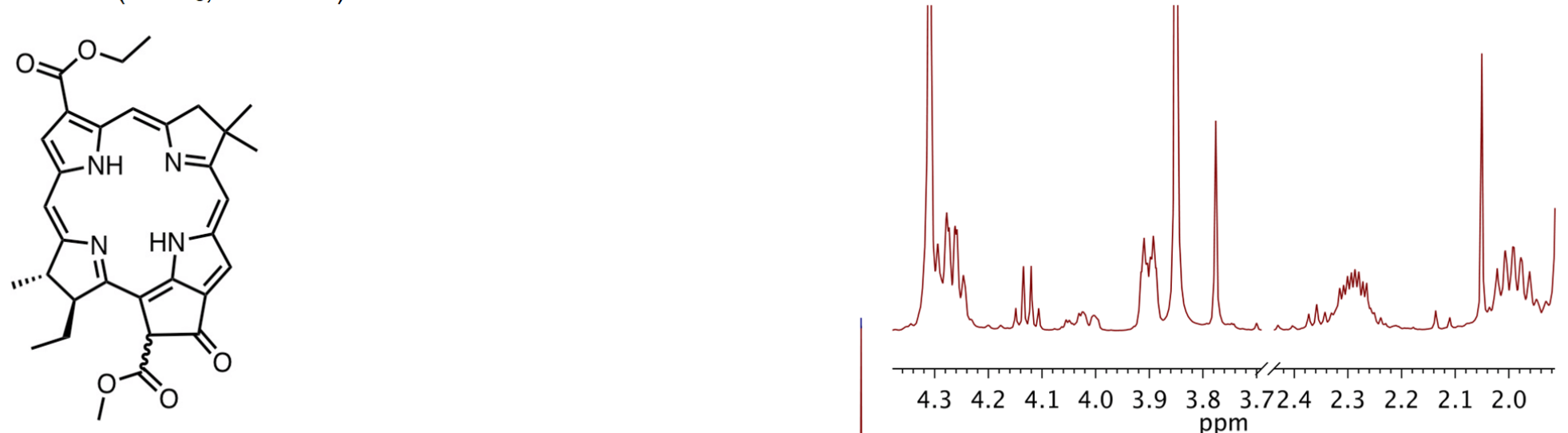

BC-1

A mixture of two epimers

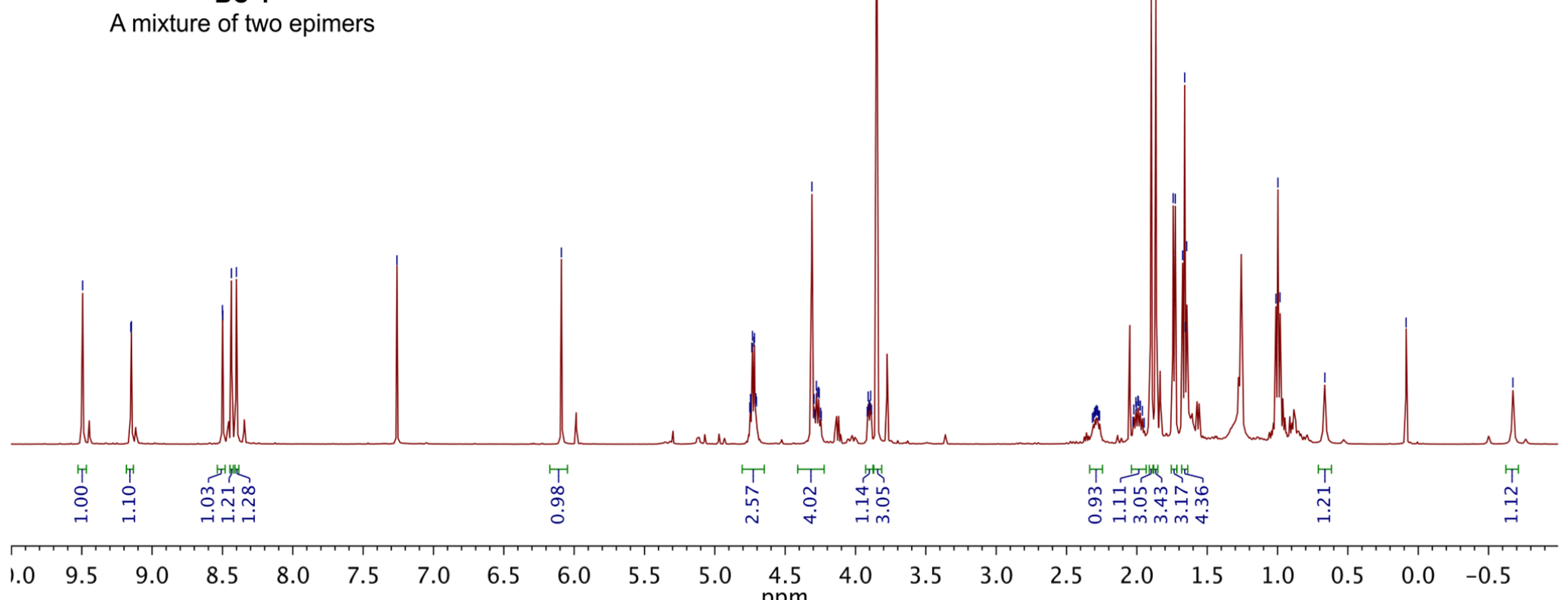




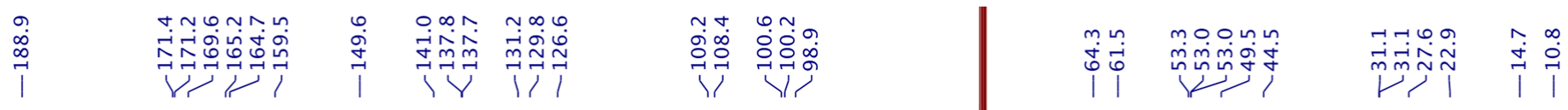

${ }^{13} \mathrm{C}\left\{{ }^{1} \mathrm{H}\right\} \mathrm{NMR}\left(\mathrm{CDCl}_{3}, 125 \mathrm{MHz}\right)$

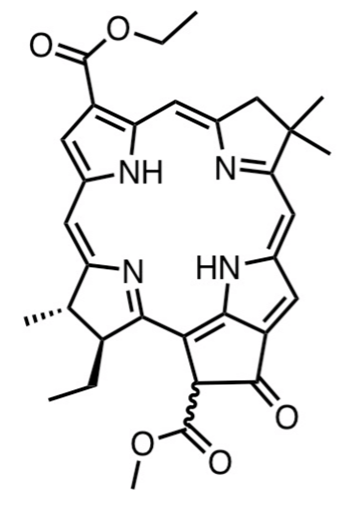

$B C-1$

A mixture of two epimers
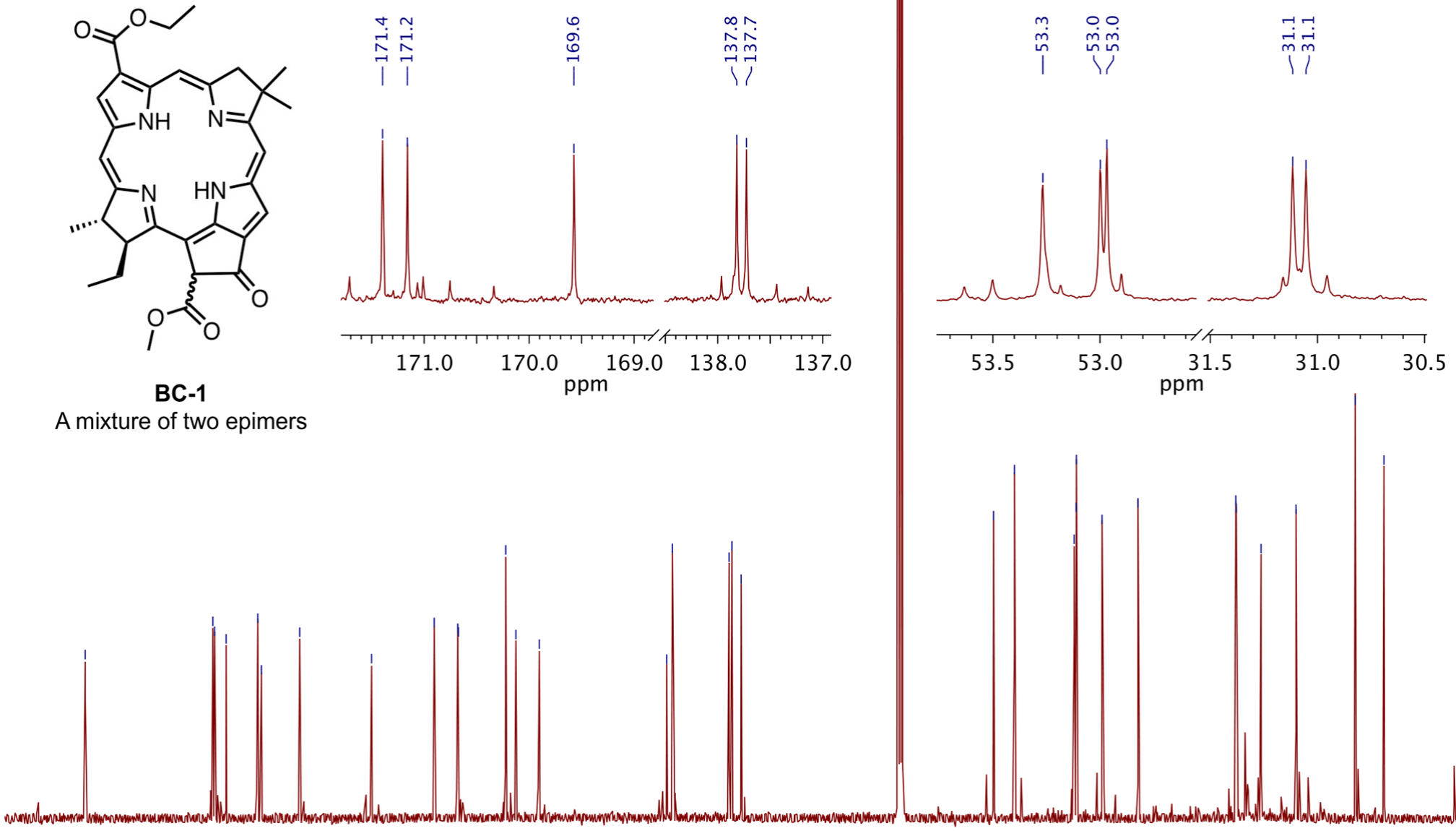

190

$180 \quad 170$

$160 \quad 150$

$140 \quad 130$

120

$110 \quad 100$

100
$\mathrm{ppm}$

80

60

50

30 


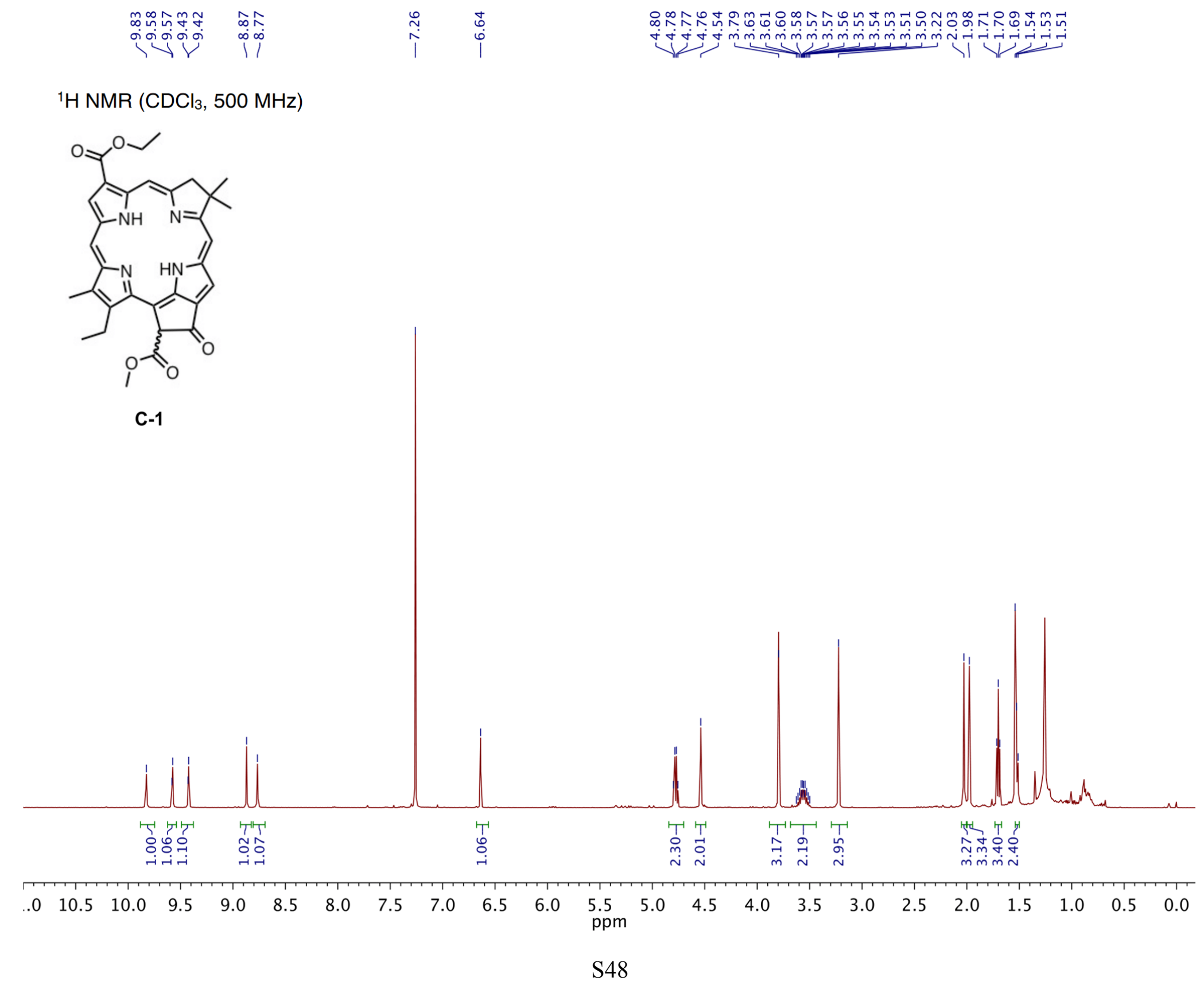




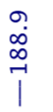
$\begin{array}{ll}0 & 0 \\ \dot{0} & \dot{0} \\ 0 & 0 \\ \mid & 0 \\ \mid & \mid\end{array}$

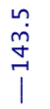

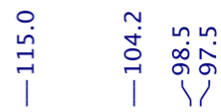

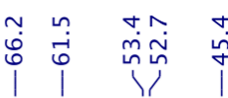
लंग्रे
$\vec{i}$

${ }^{13} \mathrm{C}\left\{{ }^{1} \mathrm{H}\right\} \operatorname{NMR}\left(\mathrm{CDCl}_{3}, 125 \mathrm{MHz}\right)$

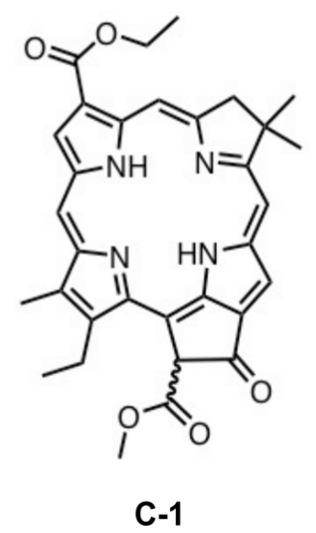

1.

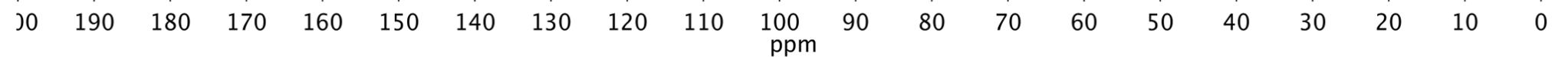

